Article

\title{
On the Adequacy of Representing Water Reflectance by Semi-Analytical Models in Ocean Color Remote Sensing
}

\author{
Jing Tan ${ }^{1, * \mathbb{C}}$, Robert Frouin ${ }^{1} \mathbb{C}$, Didier Ramon ${ }^{2}$ and François Steinmetz ${ }^{2} \mathbb{D}$ \\ 1 Scripps Institution of Oceanography, University of California, San Diego, 9500 Gilman Drive, \\ La Jolla, CA 92093, USA; rfrouin@ucsd.edu \\ 2 HYGEOS, Euratechnologies, 165 Avenue de Bretagne, 59000 Lille, France; dr@hygeos.com (D.R.); \\ fs@hygeos.com (F.S.) \\ * Correspondence: jit079@ucsd.edu; Tel.: +1-858-822-1416
}

Received: 29 October 2019; Accepted: 22 November 2019; Published: 28 November 2019

\begin{abstract}
Deterministic or statistical inversion schemes to retrieve ocean color from space often use a simplified water reflectance model that may introduce unrealistic constraints on the solution, a disadvantage compared with standard, two-step algorithms that make minimal assumptions about the water signal. In view of this, the semi-analytical models of Morel and Maritorena (2001), MM01, and Park and Ruddick (2005), PR05, used in the spectral matching POLYMER algorithm (Steinmetz et al., 2011), are examined in terms of their ability to restitute properly, i.e., with sufficient accuracy, water reflectance. The approach is to infer water reflectance at MODIS wavelengths, as in POLYMER, from theoretical simulations (using Hydrolight with fluorescence and Raman scattering) and, separately, from measurements (AERONET-OC network). A wide range of Case 1 and Case 2 waters, except extremely turbid waters, are included in the simulations and sampled in the measurements. The reflectance model parameters that give the best fit with the simulated data or the measurements are determined. The accuracy of the reconstructed water reflectance and its effect on the retrieval of inherent optical properties (IOPs) is quantified. The impact of cloud and aerosol transmittance, fixed to unity in the POLYMER scheme, on model performance is also evaluated. Agreement is generally good between model results and Hydrolight simulations or AERONET-OC values, even in optically complex waters, with discrepancies much smaller than typical atmospheric correction errors. Significant differences exist in some cases, but having a more intricate model (i.e., using more parameters) makes convergence more difficult. The trade-off is between efficiency/robustness and accuracy. Notable errors are obtained when using the model estimates to retrieve IOPs. Importantly, the model parameters that best fit the input data, in particular chlorophyll-a concentration, do not represent adequately actual values. The reconstructed water reflectance should be used in bio-optical algorithms. While neglecting cloud and aerosol transmittances degrades the accuracy of the reconstructed water reflectance and the retrieved IOPs, it negligibly affects water reflectance ratios and, therefore, any variable derived from such ratios.
\end{abstract}

Keywords: water reflectance; POLYMER; ocean color; atmospheric correction; MODIS; AERONET-OC

\section{Introduction}

Ocean color depends on the absorption and scattering properties of the constituents of the water body. Observation of spectral water reflectance from space is a major tool to gather information about water constituents and associated biogeochemical processes such as primary production. A number of atmospheric correction algorithms have been proposed to remove the influence of the atmosphere and 
surface in the satellite imagery and, therefore, retrieve the water signal (see e.g., [1]). One approach is to determine simultaneously the key properties of aerosols and water constituents of the coupled system by obtaining a best fit to the measured top-of-atmosphere (TOA) reflectance [2-6]. The advantage of this approach, compared with the standard two-step algorithm first suggested by [7], resides in its ability to manage situations of both Case 1 and Case 2 waters, i.e., waters whose inherent optical properties (IOPs) are either dominated by phytoplankton or markedly influenced by other constituents (colored dissolved organic matter and inorganic mineral particles), respectively, but this requires that the selected water reflectance model should be able to represent well the bio-optical variability across diverse aquatic ecosystems. Such atmospheric correction algorithms, whether deterministic or statistical, often use a simplified water reflectance model, such as the three-component model of Sathyendranath et al. [8], so that the absorption and scattering coefficients of the ocean water can be specified by a few parameters (e.g., chlorophyll concentration, backscattering and absorption coefficients at a given wavelength). The model, however, may not be representative of worldwide water conditions [9-12], since many variables affecting reflectance are fixed at some average values. It is generally preferable to make no assumption about the variable to retrieve. Such model may affect the retrieval of water reflectance and the accuracy of the derived ocean color products.

Steinmetz et al. [13] developed an algorithm called POLYMER to perform atmospheric correction in regions affected by sun glint and retrieve the spectrum of water reflectance. The POLYMER algorithm relies on two models: one is a simple polynomial atmospheric model fitting the scattering of the atmosphere and sun glint signal, and the other is a bio-optical water reflectance model. A spectral matching method is used to obtain the best fit of the TOA reflectance, and the water reflectance model parameters are retrieved in an iterative process. The POLYMER algorithm works effectively in the presence of Sun glint and thin clouds, increasing the useful coverage of satellite measurements. The European Space Agency (ESA) has selected POLYMER for operational generation of OC-CCI (Ocean Colour Climate Change Initiative) products $[14,15]$. One can choose from two water reflectance models in the POLYMER code: A modified version of the semi-analytical model of Morel and Maritorena [16], denoted MM01, and the semi-analytical model of Park and Ruddick [17], denoted PR05. The PR05 model is used as default in the latest version of the POLYMER code and the MM01 model is provided for optional usage. The MM01 model, slightly modified, depends on chlorophyll-a concentration and a backscattering coefficient for non-algal particles. The PR05 model depends on chlorophyll-a concentration, a parameter specifying the contribution of algal and non-algal particles to the backscattering coefficient, and a parameter allowing different absorption coefficients for dissolved organic matter. Accurate representation of the water reflectance is crucial to the success of the POLYMER algorithm. The adequacy of those models, therefore, needs to be assessed.

The objective of this study is to examine MM01 and PR05 in terms of their ability to represent properly water reflectance in a POLYMER-type inversion scheme applied to typical ocean-color sensors measuring in the spectral range $400-900 \mathrm{~nm}$. The models are first evaluated theoretically, using Hydrolight simulations with IOPs specified from an IOCCG synthesized dataset [18], and then experimentally, using AERONET-OC measurements [19]. For this, POLYMER is applied to the simulated data or the measurements assuming no interference of the atmosphere and/or surface. The accuracy of the reconstructed water reflectance is quantified, as well as its influence on the derived IOPs using the Quasi-Analytical Algorithm (QAA) [20]. The impact of cloud and aerosol transmittance on the retrieval of water reflectance, neglected in POLYMER, is also evaluated.

\section{Materials and Methods}

\subsection{Reflectance Models}

The original MM01 model [16] is slightly modified by taking into account the absorption and backscattering of non-algal particles. The MM01 model uses two parameters: the chlorophyll-a concentration ([Chla]) and the backscattering coefficient of non-algal particles (bbs), which varies 
spectrally in $\lambda^{-1}$ ( $\lambda$ is the wavelength). This allows applicability to Case 2 water situations. The model input also includes sun and sensor viewing geometry and wind speed. Specifically, the input geometry was set to match that of the specific dataset described later and the default value of wind speed was used, i.e., $5 \mathrm{~m} / \mathrm{s}$, as done in POLYMER. The output of this model is the spectral irradiance reflectance just below the surface, from which remote sensing reflectance, $R_{r s}$, is deduced. In the transformation, the $f / Q$ correction is performed according to Morel and Gentili [21]. The similarity spectrum of Ruddick et al. [22] is used to extend the model from 700 to $900 \mathrm{~nm}$.

The PR05 model is built from radiative transfer simulations for a wide range of IOPs that cover both Case 1 and Case 2 waters [17]. It is based on a generic parameterization of reflectance as a function of the total backscattering coefficients over the sum of the total absorption coefficients and the total backscattering coefficients. The PR05 model depends on three parameters: [Chla], a phase function parameter defined by the contribution of suspended particles to the backscattering coefficient $(f b)$, and a parameter allowing different absorption coefficients for dissolved organic matter ( $f a$ ). In POLYMER the default setting of the PR05 model is using [Chla] and $f b$ as free parameters and fixing $f a$ to 1 . In this study, the PR05 model with both two and three free parameters was evaluated. Raman scattering is taken into account in the variant used, by applying Raman correction coefficients from Westberry et al. [23]. The model input also includes sun and sensor viewing geometry, which were set to match the geometry of the specific dataset described later. The default wind speed is $5 \mathrm{~m} / \mathrm{s}$. The output of this model is the spectral bidirectional water reflectance just above the surface $\left(R_{w}\right)$, defined as $\pi L_{w} / E_{d}$ where $L_{w}$ is water-leaving radiance and $E_{d}$ the downward solar irradiance just above the surface, from which $R_{r s}=L_{w} / E_{d}$ is deduced by dividing by $\pi$.

\subsection{Inversion Scheme}

The model parameters, i.e., [Chla] and $b b s$ in MM01, and [Chla], $f a$, and $f b$ in PR05, are obtained from the prescribed $R_{r s}$ at a set of wavelengths in the $400-900 \mathrm{~nm}$ spectral range using, as in POLYMER, the Nelder-Mead optimization scheme [24]. A simplex method is used to minimize the cost function $f$, which is defined as:

$$
f=\sum\left(\pi \check{R}_{r s}\left(\lambda_{\mathrm{i}}\right)-\pi R_{r s}\left(\lambda_{\mathrm{i}}\right)\right)^{2} / \text { norm, norm }=0.005 \text { if } \pi R_{r s}\left(\lambda_{\mathrm{i}}\right)<0.005, \text { otherwise norm }=\pi \check{R}_{r s}\left(\lambda_{\mathrm{i}}\right),
$$

where $\check{R}_{r s}\left(\lambda_{\mathrm{i}}\right)$ is the modeled remote sensing reflectance at wavelength $\lambda_{\mathrm{i}}$, and $R_{r s}\left(\lambda_{\mathrm{i}}\right)$ is the Hydrolight simulated or field measured remote sensing reflectance at wavelength $\lambda_{\mathrm{i}}$. For the MM01 model, the first iteration simplex is defined by initial values $\log _{10}([\mathrm{Chla}])=-1$ and $b b s=0$, and initial steps 0.05 and $0.0005 \mathrm{~m}^{-1}$. For the PR05 model, the first iteration simplex is defined by initial values $\log _{10}([$ Chla $])=-1, \log _{10}(f b)=0$ and initial steps 0.2 and 0.2 when using two parameters, or by initial values $\log _{10}([$ Chla $])=-1, \log _{10}(f b)=0, \log _{10}(f a)=0$ and initial steps $0.2,0.2$, and 0.2 when using three parameters. The optimization scheme stops when $f$ reaches a threshold value of 0.005 or the iteration reaches a maximum number.

\subsection{Data Source}

Two datasets were used in this study to evaluate the performance of the MM01 and PR05 water reflectance models, i.e., their ability to properly reconstruct a prescribed water reflectance spectrum. One dataset was obtained from radiative transfer simulations, the other from measurements at a variety of coastal sites.

The first dataset contained 500 cases generated using Hydrolight. These cases cover a wide range of Case 1 and Case 2 waters, but do not include extremely turbid water situations, such as those encountered in estuaries and inland water bodies. The simulations were made from 300 to $900 \mathrm{~nm}$ at $10 \mathrm{~nm}$ intervals. The input data including the IOPs and concentrations of phytoplankton, colored dissolved organic matter (CDOM), and detritus/minerals were taken from the synthesized dataset from IOCCG Report 5 [18]. The IOCCG synthesized dataset only provides IOPs at the 
wavelength range of $400-800 \mathrm{~nm}$ at $10 \mathrm{~nm}$ intervals. To extend the IOP values to the wavelengths below $400 \mathrm{~nm}$ (necessary to account for Raman scattering) and above $800 \mathrm{~nm}$ the following procedures were applied:

- Phytoplankton absorption. The phytoplankton absorption, $a_{p h}$, is expressed as $a_{p h}=$ [Chla] $a_{p h}^{*}$, where $a_{p h}^{*}$ is the chlorophyll-specific absorption coefficient, both provided in the IOCCG dataset. The values of $a_{p h}^{*}$ at 350-400 nm were adopted from Morel [25] and extrapolated to $300 \mathrm{~nm}$, which was then normalized to the IOCCG $a_{p h}^{*}$ value at $400 \mathrm{~nm}$ to ensure continuity. The $a^{*}{ }_{p h}$ values in the $800-900 \mathrm{~nm}$ range were assumed constant and fixed at the value at $800 \mathrm{~nm}$.

- CDOM absorption. The CDOM absorption, $a_{g}$, was modeled as $a_{g}(\lambda)=a_{g}(440) \exp \left(-S_{g}(\lambda-440)\right)$, with $S_{g}$ and $a_{g}(440)$ provided by IOCCG [18].

- Detritus/mineral absorption. The absorption of detritus/mineral, $a_{d m}$, was modeled as $a_{d m}(\lambda)=$ $a_{d m}(440) \exp \left(-S_{d m}(\lambda-440)\right)$, with $S_{d m}$ and $a_{d m}(440)$ provided by IOCCG [18].

- Backscattering of phytoplankton. The attenuation of phytoplankton, $c_{p h}$, was modeled as $c_{p h}=c_{p h}(550)(550 / \lambda)^{\mathrm{n} 1}$ in the IOCCG dataset. The value of $\mathrm{n} 1$ was determined using $c_{p h}$ at $400-800 \mathrm{~nm}$, which was then used to extend $c_{p h}$ to $300-1000 \mathrm{~nm}$. The backscattering of phytoplankton, $b b_{p h}$, was thus obtained using $b b_{p h}=\widetilde{b}_{p h}\left(c_{p h}-a_{p h}\right)$ with $\widetilde{b}_{p h}$ equal to 0.01 .

- Backscattering of detritus, mineral, and other particles. The backscattering of detritus, mineral, and others, $b b_{d m}$, was modeled as $b b_{d m}=b b_{d m}(550)(550 / \lambda)^{\mathrm{n} 2}$. The value of $\mathrm{n} 2$ was determined using $b b_{d m}$ at $400-800 \mathrm{~nm}$, which was then used to extend $b b_{d m}$ to $300-900 \mathrm{~nm}$.

All simulations were done with a solar zenith angle of $30^{\circ}$ and a wind speed of $5 \mathrm{~m} / \mathrm{s}$. Pure seawater properties were specified by Pope and Fry [26] and Smith and Baker [27] for absorption and scattering, respectively. Clear sky condition and infinitely deep homogeneous water were assumed. The direct and diffuse solar irradiance were simulated using a semi-empirical sky model [28] with the annual average sun-earth distance and ozone content of 300 DU as input. Raman scattering and chlorophyll and CDOM fluorescence were also included in all simulations. The simulated nadir-viewed remote sensing reflectance, $R_{r s}$, was further interpolated into MODIS wavelengths $(412,443,488,531,547$, $667,678,748$, and $869 \mathrm{~nm}$ ). Note that the IOCCG synthesized IOPs do not cover all possible natural waters. However, as the models and parameters of describing input IOPs are based on extensive field measurements of oligotrophic and eutrophic waters [8,29-35], the Hydrolight simulated data should be consistent with a wide range of field observations.

The second dataset originated from the ocean color component of the Aerosol Robotic Network (AERONET-OC), which provides consistent and accurate long-term measurements collected by globally distributed autonomous radiometer systems deployed on offshore fixed platforms [19]. In the AERONET-OC dataset, the normalized water-leaving radiance $L_{W N}(\lambda)$ at various wavelengths in the visible and near-infrared spectral regions is the primary ocean color radiometric product. Data at quality-assurance level 2.0, normalized to the geometry of the Sun at zenith and the view at nadir, was used. The level 2.0 data is fully quality controlled including pre- and post-field calibration with differences smaller than $5 \%$, automatic cloud removal, and manual inspection. Conversion to $R_{r s}$ was accomplished by multiplying $L_{W N}(\lambda)$ by extraterrestrial solar irradiance. Note that uncertainties in the AERONET-OC in-situ measurements are about $5 \%$ in the blue to green bands, and about $8 \%$ in the red band [19]. The AERONET-OC measurements were collected using different radiometric instruments and thus the wavelengths used were not exactly the same. Since in this study $R_{r s}$ at MODIS wavelengths (see above) are considered, and since the simulated data set corresponds to those wavelengths, measurements at wavelengths located within the MODIS center wavelengths $\pm 3 \mathrm{~nm}$ were selected. At some of the AERONET-OC sites, in particular the Venise site $\left(45^{\circ} \mathrm{N}, 12^{\circ} \mathrm{E}\right)$, measurements at $547 \pm 3 \mathrm{~nm}$ were missing. In the end measurements from a total of fourteen sites were used, including twelve coastal sites, i.e., COVE_SEAPRISM $\left(36^{\circ} \mathrm{N}, 75^{\circ} \mathrm{W}\right)$, Gageocho_Station $\left(33^{\circ} \mathrm{N}, 124^{\circ} \mathrm{E}\right)$, Ieodo_Station $\left(32^{\circ} \mathrm{N}, 125^{\circ} \mathrm{E}\right)$, Socheongcho $\left(37^{\circ} \mathrm{N}, 124^{\circ} \mathrm{E}\right)$, Galata_Platform $\left(43^{\circ} \mathrm{N}, 28^{\circ} \mathrm{E}\right), \mathrm{GOT}$ SSEAPRISM $\left(9^{\circ} \mathrm{N}, 101^{\circ} \mathrm{E}\right), \operatorname{LISCO}\left(43^{\circ} \mathrm{N}, 70^{\circ} \mathrm{W}\right)$, Lucinda $\left(18^{\circ} \mathrm{S}, 146^{\circ} \mathrm{E}\right)$, 
Thornton_C-Power $\left(51^{\circ} \mathrm{N}, 2^{\circ} \mathrm{E}\right), \mathrm{USC}_{-}$SEAPRISM $\left(33^{\circ} \mathrm{N}, 118^{\circ} \mathrm{W}\right)$, WaveCIS_site_CSI_6 $\left(28^{\circ} \mathrm{N}, 90^{\circ} \mathrm{W}\right)$, and Zeebrugge-MOW1 $\left(51^{\circ} \mathrm{N}, 2^{\circ} \mathrm{E}\right)$, and two lake sites, i.e., Lake_Erie $\left(41^{\circ} \mathrm{N}, 83^{\circ} \mathrm{W}\right)$ and Palgrunden $\left(58^{\circ} \mathrm{N}, 13^{\circ} \mathrm{E}\right)$. Additional criteria based on the similarity spectrum [22] were applied to check and remove outliers, i.e., only the data for which (i) $R_{r s}(869 \mathrm{~nm})>-0.0001 \mathrm{sr}^{-1}$ and (ii) the ratio $R_{r s}(667 \mathrm{~nm}) / R_{r s}(869 \mathrm{~nm})>3$ if $R_{r s}(869 \mathrm{~nm})>0.0008 \mathrm{sr}^{-1}$ were selected. This resulted in a total number of $9824 R_{r s}$ measurements at wavelengths close to the MODIS wavelengths. For simplification, the AERONET-OC wavelengths will be referred to as 412, 443, 488, 531, 547, 667, and $869 \mathrm{~nm}$, i.e., the MODIS wavelengths. The AERONET-OC measurements were made only under clear sky conditions. They were collected when wind speed is less than $15 \mathrm{~m} / \mathrm{s}$. Chlorophyll- $a$ concentrations are provided in the AERONET-OC dataset, but not from field measurements; they are estimated through an iterative procedure making use of reflectance band ratios [19]. AERONET-OC sites for which band-ratio algorithms exist naturally benefit from those regional algorithms. For several AERONET-OC sites, the lack of regional algorithms imposes the application of the standard OC2V4 band-ratio. Because of this, the expected accuracy of AERONET-OC [Chla] varies from site to site.

\section{Results and Discussion}

\subsection{Model Performance with Hydrolight Simulations}

Model performance (MM01, PR05) was first evaluated theoretically using the Hydrolight simulations. Prior to evaluation, Case 1 and Case 2 waters were separated. Distinguishing Case 1 and Case 2 waters was based on the criteria proposed by Morel and Bélanger [36] and Robinson et al. [37]. According to Morel and Bélanger [36], the particulate scattering coefficient at $560 \mathrm{~nm}, b_{p}(560)$, increases with increasing [Chla]. The upper limit of $b_{p}(560)$ can be expressed as

$$
b_{p}(560)=0.69[\text { Chla }]^{0.766}
$$

Such a relationship was used as input to the bio-optical model of Morel and Maritorena [13] to generate the threshold water irradiance reflectance just beneath the water surface, $R_{w}(560)$, as a function of [Chla]. The effect of solar zenith angle was taken into consideration. For a given [Chla], if the observed $R_{w}(560)$ exceeded the threshold $R_{w}(560)$, the water was determined as Case 2 , otherwise as Case 1. Note that the threshold of Morel and Bélanger [36] only distinguishes Case 2 turbid water with excessive sediments and detritus and does not separate yellow substance-dominated Case 2 waters. Therefore, the determined Case 1 water situations still included yellow substance-dominated Case 2 water situations. An additional threshold of remote sensing reflectance at $670 \mathrm{~nm}$, i.e., $R_{r s}(670)>0.0012$ $\mathrm{sr}^{-1}$, now adopted as turbid water flag by the NASA Ocean Biology Processing Group (starting with the fourth processing), was also applied [37]. This second threshold may still not favor the identification of CDOM-dominated waters. With these two criteria, there are a total of 55 spectra classified as Case 1 and 445 spectra as Case 2 (Figure 1). Statistics including number of points $(\mathrm{N})$, bias, root-mean-squared error (RMSE), and coefficient of determination $\left(R^{2}\right)$ were used to evaluate the model performance.

Figure 2 shows some examples of $R_{r s}$ spectra reconstructed using the MM01 and PR05 models. Only 2 variable parameters, i.e., [Chla] and $f b$, are used in PR05, with $f a$ fixed to 1 . The MM01 and PR05 spectra generally agree with the Hydrolight simulated spectra, especially for Case 1 water (Figure 2a-c). As [Chla] is increased (Figure 2b,c), the difference between reconstructed and simulated $R_{r s}$ around $680-700 \mathrm{~nm}$ becomes larger. This is expected since chlorophyll fluorescence effects are not considered in both models. The ability of the model to reproduce properly $R_{r s}$ is degraded for Case 2 water (Figure 2d-f). In the complex Case 2 situation of Figure 2f, one noticeable feature of the MM01 reconstructed $R_{r s}$ is the large discrepancy at 400-500 nm and 600-650 nm, which is attributed to neglecting CDOM absorption and crudely parameterizing the backscattering by non-algal particles. The disagreement around 550-650 nm between PR05 reconstructed and Hydrolight simulated $R_{r s}$ is due to the fact that the slope of CDOM absorption adopted in the PR05 model, modeled as a function 
of [Chla], does not reflect well the actual (i.e., prescribed) slope, which ultimately affects the red wavelengths since the spectral-matching scheme minimizes the overall difference.
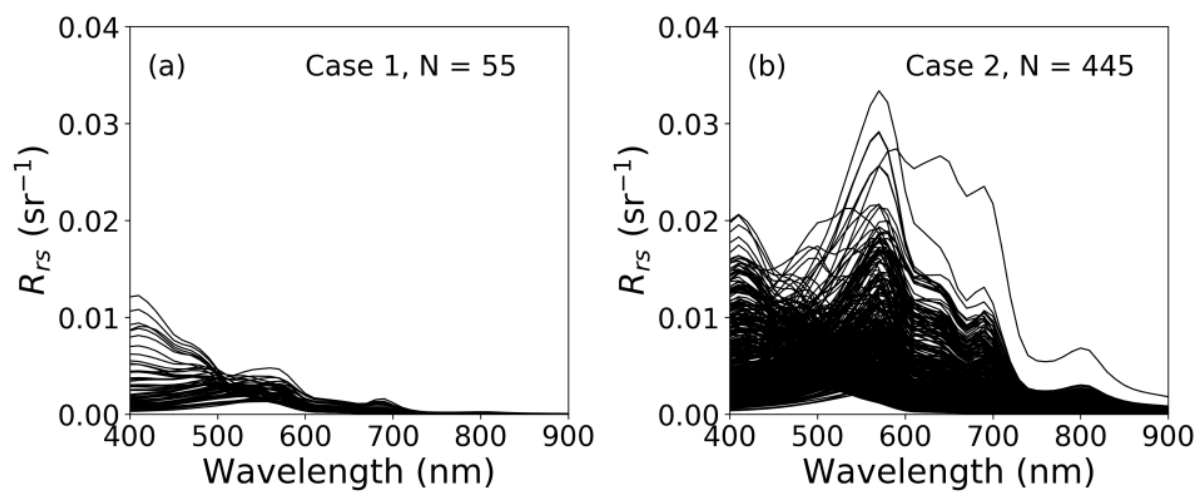

Figure 1. Spectra of remote sensing reflectance $R_{r s}$ for Case 1 (a) and Case 2 (b) water using Hydrolight simulations. To distinguish Case 1 and 2 water situations, two thresholds were used: the threshold of Morel and Bélanger [32], i.e., the limiting $R_{w}(560)$ values produced by the bio-optical model of Morel and Maritorena [13] with the upper limit of $b_{p}(560)=0.69[\mathrm{Chla}]^{0.766}$ as input, and the threshold of Robinson et al. [33], i.e. $R_{r s}(670) \leq 0.0012 \mathrm{sr}^{-1}$ for Case 1 water, otherwise Case 2 water.
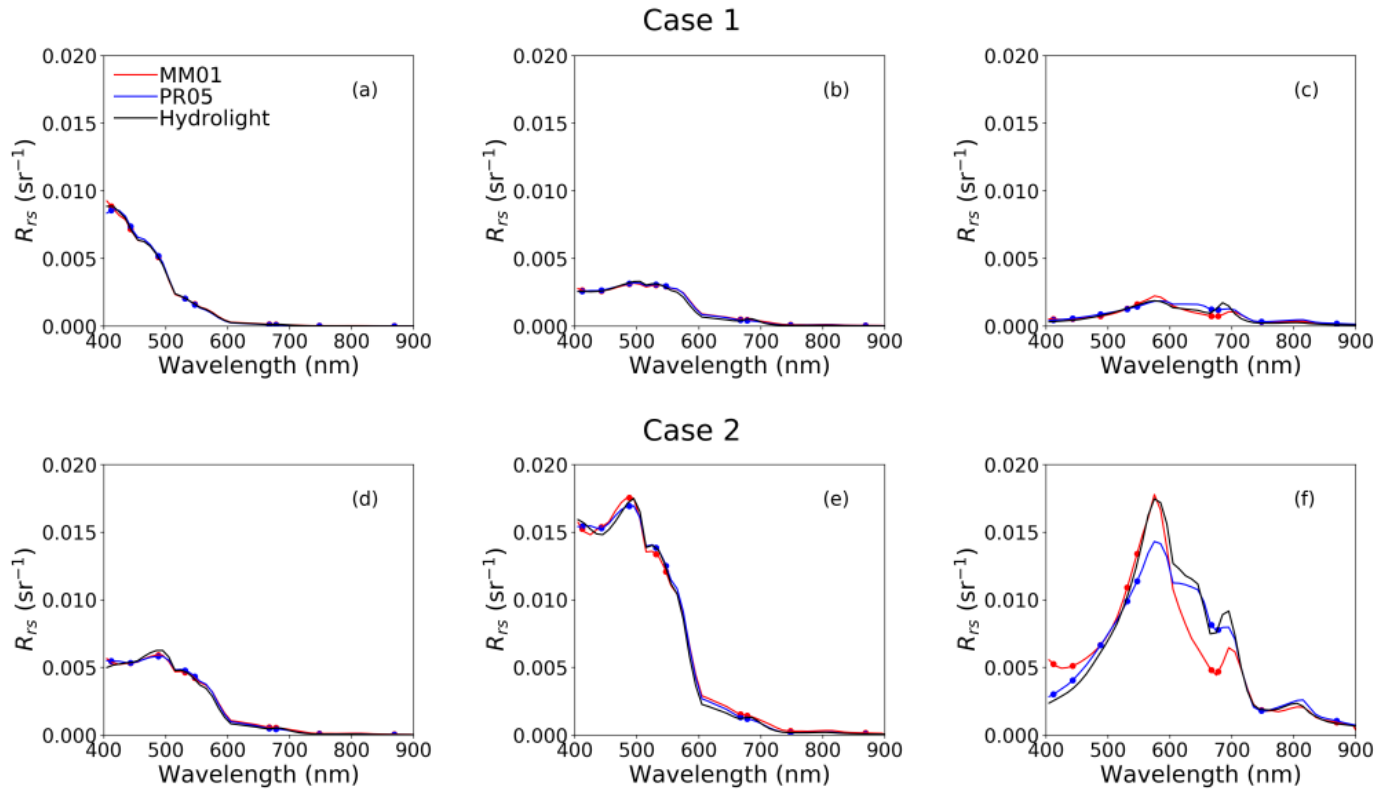

Figure 2. Examples of MM01 and PR05 reconstructed $R_{r s}$ spectra versus Hydrolight simulated $R_{r s}$ spectra, for Case $1(\mathbf{a}-\mathbf{c})$ and Case $2(\mathbf{d}-\mathbf{f})$ water situations. The spectral matching procedure was performed at MODIS wavelengths $(412,443,488,531,547,667,678,748$, and $869 \mathrm{~nm})$, and the retrieved model parameters were then used to produce modeled $R_{r s}$ spectra from $400 \mathrm{~nm}$ to $900 \mathrm{~nm}$ at $10 \mathrm{~nm}$ interval. Black lines represent Hydrolight simulations, red lines represent MM01 reconstructed $R_{r s}$ spectra, and blue lines PR05 reconstructed $R_{r s}$ spectra. The dots show model reconstructed $R_{r s}$ at MODIS wavelengths.

Figure 3 displays scatter plots of MM01 and PR05 reconstructed $R_{r s}$ versus Hydrolight simulated $R_{r s}$ at selected wavelengths, i.e., 443, 488, 547, and $667 \mathrm{~nm}$, for all cases. The MM01 model performs generally well in reproducing $R_{r s}$ at 443,488 , and $547 \mathrm{~nm}$, with the performance for Case 1 water (Figure 3 , blue) being better than that for Case 2 water (Figure 3, red), with overall bias and Root-Mean-Squared Error (RMSE) of $0.00038(7.7 \%)$ and $0.00082 \mathrm{sr}^{-1}(16.5 \%)$ at $443 \mathrm{~nm},-0.00016(-2.7 \%)$ and $0.00070 \mathrm{sr}^{-1}$ $(11.9 \%)$ at $488 \mathrm{~nm}, 0.00013(2.1 \%)$ and $0.00075 \mathrm{sr}^{-1}(12.1 \%)$ at $547 \mathrm{~nm}$, and $-0.00039(-19.3)$ and $0.00124 \mathrm{sr}^{-1}(61.4 \%)$ at $667 \mathrm{~nm}$, respectively. The percent values in parentheses are biases or RMSEs 
normalized by the mean of the simulated data. The relatively high bias and RMSE for Case 2 water at $443 \mathrm{~nm}$ is due to the lack of CDOM absorption in the MM01 model and is consistent with Figure 2. The MM01 model performance is degraded at $667 \mathrm{~nm}$. At this wavelength, large bias and RMSE are found for Case 2 water, although the reconstruction of $R_{r s}$ is still good for Case 1 water. The degradation at $667 \mathrm{~nm}$ is due primarily to the backscattering of non-algal particles, not being sufficiently well treated by introducing $b b s$, and secondarily to fluorescence and CDOM absorption not considered. Since the spectral-matching scheme utilizes information at all the input wavelengths, neglecting CDOM absorption, influential in the blue, may also impact results in the red. The PR05 model shows better performance than the MM01 model in reconstructing $R_{r s}$ at $443,488,547$, and 667 $\mathrm{nm}$, with bias and RMSE generally reduced, i.e., $0.00024(4.8 \%)$ and $0.00038 \mathrm{sr}^{-1}(7.7 \%)$ at $443 \mathrm{~nm}$, $-0.00001(-0.1 \%)$ and $0.00039 \mathrm{sr}^{-1}(6.8 \%)$ at $488 \mathrm{~nm},-0.00030(-4.9 \%)$ and $0.00061 \mathrm{sr}^{-1}(9.8 \%)$ at $547 \mathrm{~nm}$, and $0.00015(7.6 \%)$ and $0.00027 \mathrm{sr}^{-1}(13.4 \%)$ at $667 \mathrm{~nm}$, respectively. The relatively large bias and RMSE at $547 \mathrm{~nm}$, as compared to 443 and $488 \mathrm{~nm}$, is due to the CDOM absorption slope, which is not adequately represented, as well as the spectral-matching scheme that minimizes the overall difference. The reconstructed $R_{\mathrm{rs}}$ at $667 \mathrm{~nm}$ is in good agreement with the Hydrolight values, which is consistent with the results shown in Figure 2. The improvement is dramatic at this wavelength when using PR05 instead of MM01 (e.g., RMSE reduced from $61.4 \%$ to $13.4 \%$ ).
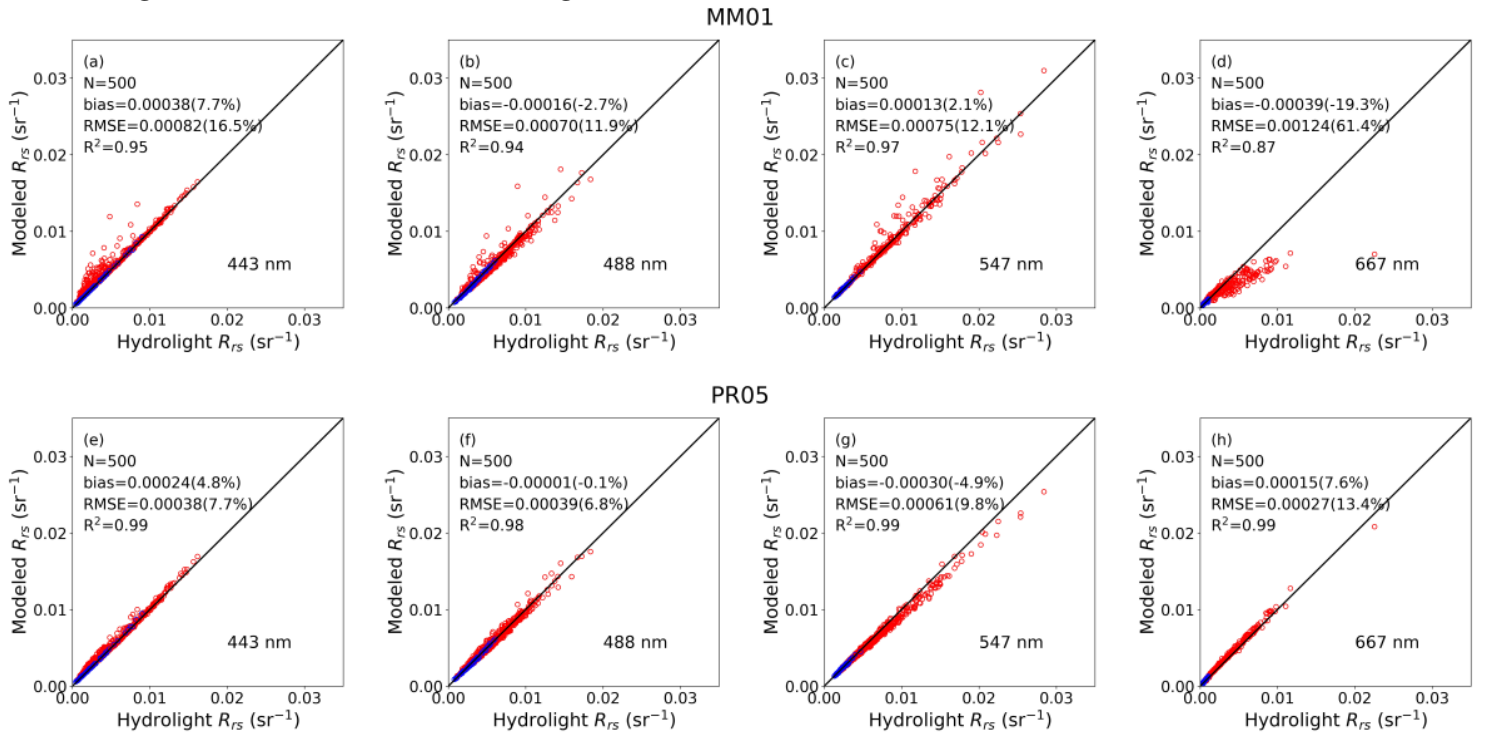

Figure 3. Comparison of MM01 (a-d) and PR05 (e-h) reconstructed remote sensing reflectance $R_{r s}$ with Hydrolight simulated $R_{r s}$ at selected MODIS wavelengths: $443 \mathrm{~nm}, 488 \mathrm{~nm}, 547 \mathrm{~nm}$, and $667 \mathrm{~nm}$. Blue circles represent Case 1 water and red represent Case 2 water.

Performance statistics were computed separately for Case 1 and Case 2 water situations at all MODIS wavelengths (Table 1). The model results generally agree with the Hydrolight values, even in optically complex waters, with PR05 outperforming MM01 in almost all situations. Based on Table 1, the MM01 model generates $R_{r s}$ more accurately for Case 1 water than for Case 2 water from $412 \mathrm{~nm}$ to $547 \mathrm{~nm}$ as the bias and RMSE values are lower, which is consistent with Figures 2 and 3. The bias and RMSE for Case 1 water are less than $4.0 \%$ and $6.0 \%$, respectively, while the bias can increase to $17.0 \%$ and the RMSE to $26.1 \%$ for Case 2 water. As wavelength becomes longer, i.e., from $667 \mathrm{~nm}$ to $869 \mathrm{~nm}$, the bias and RMSE error increase for both Case 1 and Case 2 water situations. The reconstruction of $R_{r s}$ at near infrared wavelengths, i.e., 748 and $869 \mathrm{~nm}$, show large bias and RMSE (up to 45.6\% and 78.3\%, respectively). This is due mostly to the simplified treatment of non-algal particles via the addition of a backscattering coefficient with spectral dependence in $\lambda^{-1}$ (and no absorption). Extending $R_{r s}$ from 700 to $900 \mathrm{~nm}$ using the average similarity spectrum for turbid waters may also introduce errors. Similarly, the PR05 model generates more accurate $R_{r s}$ estimation for Case 1 water than for Case 2 water from 
$412 \mathrm{~nm}$ to $547 \mathrm{~nm}$. At these wavelengths, the largest bias observed is $2.1 \%$ and the largest RMSE $4.8 \%$ for Case 1 water, and the bias and RMSE increase up to 5.2\% and 9.7\%, respectively, for Case 2 water. The bias and RMSE errors increase (up to $13.7 \%$ and $22.2 \%$, respectively) at 667 and $678 \mathrm{~nm}$, indicating significant degradation in $R_{r s}$ reconstruction at these wavelengths. Much larger relative errors are observed at the near infrared wavelengths, for both Case 1 and Case 2 situations, i.e., an RMSE of 47.3 and $21.7 \%$, respectively, at $748 \mathrm{~nm}$ and 102.0 and $72.6 \%$, respectively, at $869 \mathrm{~nm}$, which reflects the generally lower $R_{r s}$, especially at $869 \mathrm{~nm}$. This could also be partly due to the fact that the input absorption and scattering coefficients at these wavelengths are extrapolated values based on the values at $700 \mathrm{~nm}$ instead of based on field measurements. Compared with the POLYMER performance against in situ data obtained for the Medium Resolution Imaging Spectroradiometer (MERIS) in Case 1 water (Müller et al. [14]), the error in reconstructing $R_{r s}$ from MM01 or PR05 (Table 1) is much smaller than the algorithm error, with RMSE values of 0.00008 (MM01) and 0.00012 (PR05) instead of $0.0011 \mathrm{sr}^{-1} \mathrm{at}^{-}$ $443 \mathrm{~nm}$, and 0.00008 (MM01) and 0.00008 (PR05) at $547 \mathrm{~nm}$ instead of $0.00032 \mathrm{sr}^{-1}$ at $560 \mathrm{~nm}$. When data collected in both Case 1 and 2 waters are considered [14,38], the POLYMER RMSE values for MERIS are increased to $0.0037 \mathrm{sr}^{-1}$ and $0.0033 \mathrm{sr}^{-1}$ at 443 and $560 \mathrm{~nm}$, respectively, which is much larger than the $R_{r s}$ reconstruction errors, i.e., 0.00082 and 0.00038 at $443 \mathrm{~nm}$ and 547, respectively (Table 1). For MODIS-Aqua, these authors reported similar POLYMER performance, i.e., RMSE of 0.0036 at $443 \mathrm{~nm}$ and $0.0031 \mathrm{sr}^{-1}$ at $547 \mathrm{~nm}$. Thus, the error introduced by the semi-analytical modeling of water reflectance is unlikely to dominate the POLYMER performance, indicating that using MM01 and, especially, PR05 in the spectral-matching algorithm is adequate.

Table 1. Performance statistics of MM01 and PR05 reconstructed $R_{r s}$ for Case 1 and Case 2 water using Hydrolight simulations.

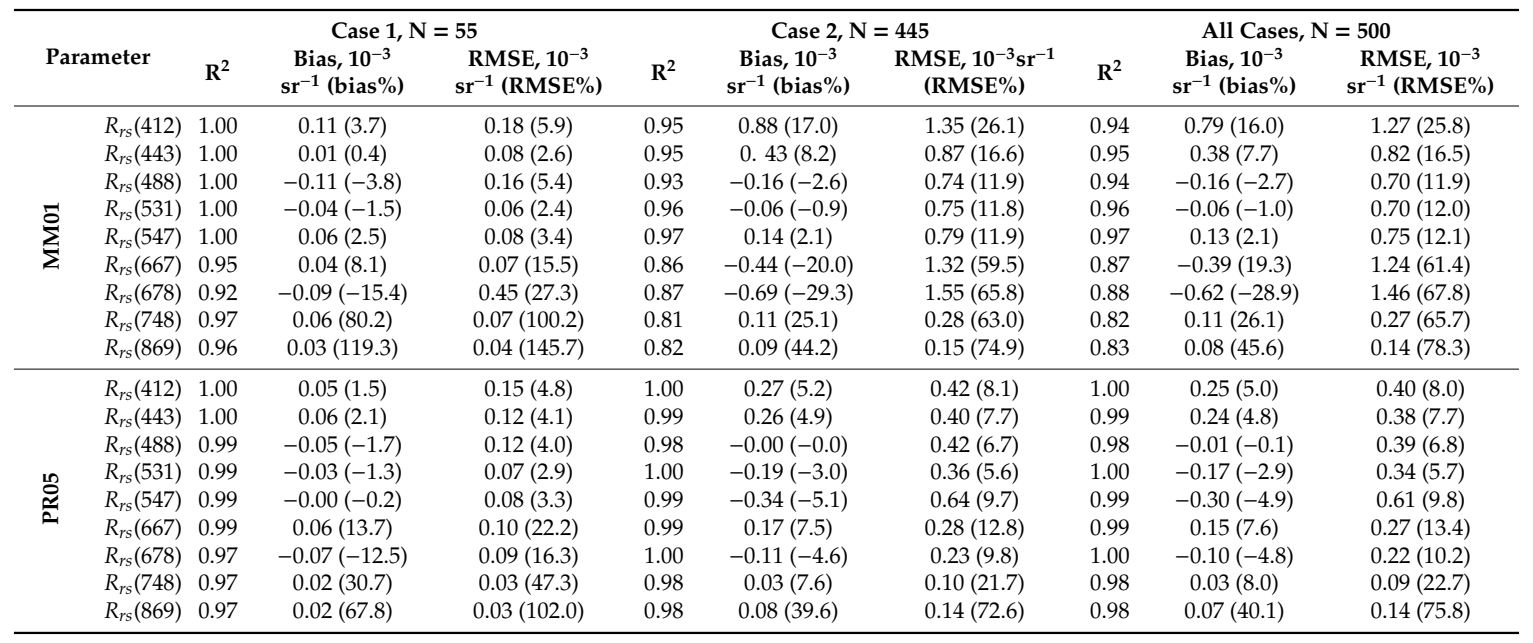

Figure 4 displays scatter plots of the model reconstructed and Hydrolight simulated $R_{r s}$ ratios. Three ratios commonly used in ocean color algorithms $[39,40]$ were selected, i.e., $R_{r s}(412) / R_{r s}(547)$, $R_{r s}(443) / R_{r s}(547)$, and $R_{r s}(488) / R_{r s}(547)$. It is found that the MM01 and PR05 modeled band ratios $R_{r s}(412) / R_{r s}(547), R_{r s}(443) / R_{r s}(547)$, and $R_{r s}(488) / R_{r s}(547)$ are all in very good agreement with the Hydrolight simulations. The overall statistics indicate that the two models perform similarly in restituting $R_{r s}$ ratios: the bias is less than 6\% and the RMSE less than 9\% for the MM01 model, and the bias is less than 5\% and the RMSE less than 10\% for the PR05 model. Also, the performance of Case 1 water situations is similar to that of Case 2 water situations (Table 2). This indicates that both the MM01 and PR05 models are capable of provide accurate estimation of $R_{r s}$ ratios, which is important for ocean-color products using band ratio algorithms. If the MM01 and PR05 reconstructed $R_{r s}$ is used in the OCI algorithm [41], the resulted bias and RMSE for estimated [Chla] are $-0.000(-0.2 \%)$ and $0.006 \mathrm{mgm}^{-3}(4.3 \%)$, and $-0.001(-0.7 \%)$ and $0.008 \mathrm{mgm}^{-3}(6.6 \%)$, respectively, i.e., much less than the errors caused by the OCI algorithm itself. This is due to the fact that the errors on $R_{\mathrm{rs}}$ at 
the various wavelengths considered in the $\mathrm{CI}$ equation, i.e., $\mathrm{CI} \approx R_{r s}(555)-0.5\left(R_{r s}(443)+R_{r s}(667)\right)$ where $R_{r s}(555)$ is specified as $0.93 R_{r s}(547)$ [41], are small (on the order of $10^{-4} \mathrm{sr}^{-1}$ ) in the applicability domain of the algorithm (clear, Case 1 waters). Note for both models the Nelder-Mead retrieved [Chla] differs substantially from the prescribed [Chla] (Figure 4). The bias and RMSE of $\log _{10}([\mathrm{Chla}]$ ) are 0.52 and 0.60, and 0.21 and 0.37, respectively, for MM01 and PR05 model, and the errors are similar for both Case 1 and Case 2 waters (Table 2). These values, especially biases, are much larger when compared with the MODIS-Aqua estimated [Chla] performance against in situ data which shows absolute bias and mean absolute error (MAE, always less or equal to RMSE) of 0.07 and 0.22 on $\log _{10}$ scale, respectively [42]. This is probably due to the variations in the relation between the absorption/ backscattering coefficients and the model parameters, which are not accounted for in the models. It is thus concluded that the [Chla] parameter in the models does not represent well the actual [Chla] and should not be used as [Chla] estimate. Instead [Chla] should be derived from the reconstructed $R_{r s}$, and using $R_{r s}$ in band-ratio or OCI algorithms is appropriate.
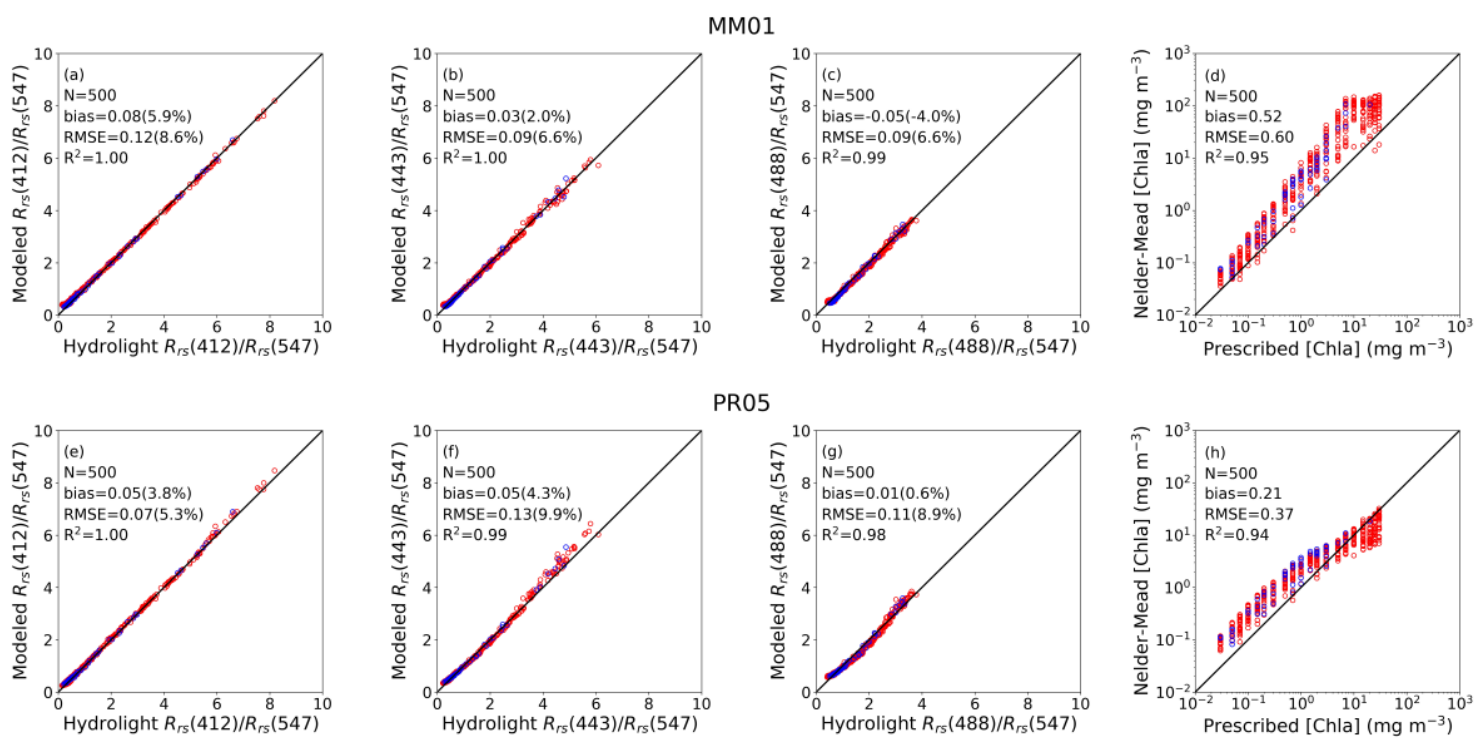

PR05
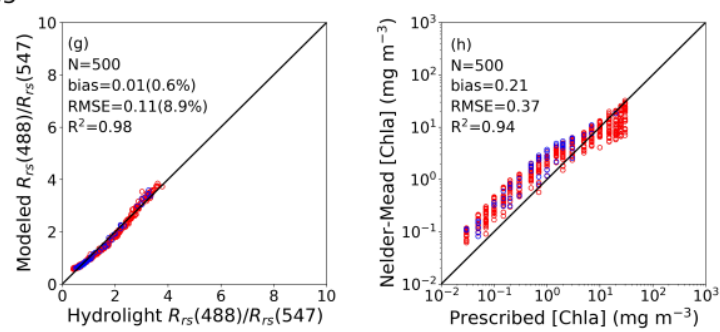

Figure 4. Comparison of MM01 (a-d) and PR05 (e-h) reconstructed and Hydrolight simulated band ratios $R_{r s}(412) / R_{r s}(547), R_{r s}(443) / R_{r s}(547)$, and $R_{r s}(488) / R_{r s}(547)$, as well as Nelder-Mead retrieved and prescribed [Chla]. Blue circles represent Case 1 water and red represent Case 2 water. The bias and RMSE of [Chla] were calculated on log10 scale.

Table 2. Performance statistics of MM01 and PR05 reconstructed $R_{r s}$ ratios and [Chla] for Case 1 and Case 2 water using Hydrolight simulations. The bias and RMSE of log10([Chla]) are in the unit of $\mathrm{mgm}^{-3}$.

\begin{tabular}{|c|c|c|c|c|c|c|c|}
\hline & \multirow[b]{2}{*}{ Parameter } & \multicolumn{3}{|c|}{ Case $1, \mathrm{~N}=55$} & \multicolumn{3}{|c|}{ Case $2, \mathrm{~N}=445$} \\
\hline & & $\mathbf{R}^{2}$ & Bias (bias\%) & RMSE (RMSE\%) & $\mathbf{R}^{2}$ & Bias (bias\%) & RMSE (RMSE\%) \\
\hline \multirow{4}{*}{$\sum_{\Sigma}^{\sigma}$} & $R_{r s}(412) / R_{r s}(547)$ & 1.00 & $0.03(2.1)$ & $0.05(3.6)$ & 1.00 & $0.09(6.5)$ & $0.13(9.2)$ \\
\hline & $R_{r s}(443) / R_{r s}(547)$ & 1.00 & $-0.04(-0.6)$ & $0.08(5.7)$ & 1.00 & $0.03(2.4)$ & $0.09(6.8)$ \\
\hline & $R_{r s}(488) / R_{r s}(547)$ & 1.00 & $-0.06(-4.6)$ & $0.09(6.9)$ & 1.00 & $-0.05(-3.9)$ & $0.08(6.6)$ \\
\hline & $\log _{10}([$ Chla $])$ & 0.94 & 0.49 & 0.56 & 0.95 & 0.52 & 0.61 \\
\hline \multirow{4}{*}{ 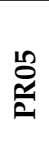 } & $R_{r s}(412) / R_{r s}(547)$ & 1.00 & $0.03(2.3)$ & $0.06(4.1)$ & 1.00 & $0.06(4.0)$ & $0.07(5.4)$ \\
\hline & $R_{r s}(443) / R_{r s}(547)$ & 1.00 & $0.04(3.1)$ & $0.14(9.9)$ & 0.99 & $0.06(4.4)$ & $0.13(9.8)$ \\
\hline & $R_{r s}(488) / R_{r s}(547)$ & 0.99 & $-0.01(-0.8)$ & $0.10(7.5)$ & 0.99 & $0.01(0.8)$ & $0.12(9.1)$ \\
\hline & $\log _{10}([$ Chla $])$ & 0.93 & 0.37 & 0.41 & 0.95 & 0.19 & 0.37 \\
\hline
\end{tabular}

As seen in Figure 5, the errors generally increase when [Chla] increases for both MM01 and PR05 models. The bias and RMSE obtained for the PR05 model are generally lower than those for the MM01 model through the entire [Chla] range, confirming that the PR05 model provides better reconstruction 
of $R_{r s}$ than the MM01 model. Specifically, the large bias and RMSE of the MM01 model, noticeably at $412 \mathrm{~nm}, 667 \mathrm{~nm}$ and $678 \mathrm{~nm}$, are mainly related to the simplified treatment of backscattering of non-algal particles, as well as lack of fluorescence and absorption of CDOM and non-algal particles in the model. The large bias and RMSE at $547 \mathrm{~nm}$ of the PR05 model is due to the non-representative CDOM absorption slope, as discussed previously. The results also suggest degraded performance for Case 2 waters since these waters have generally higher [Chla] than Case 1 waters (bias and RMSE are larger for productive waters).
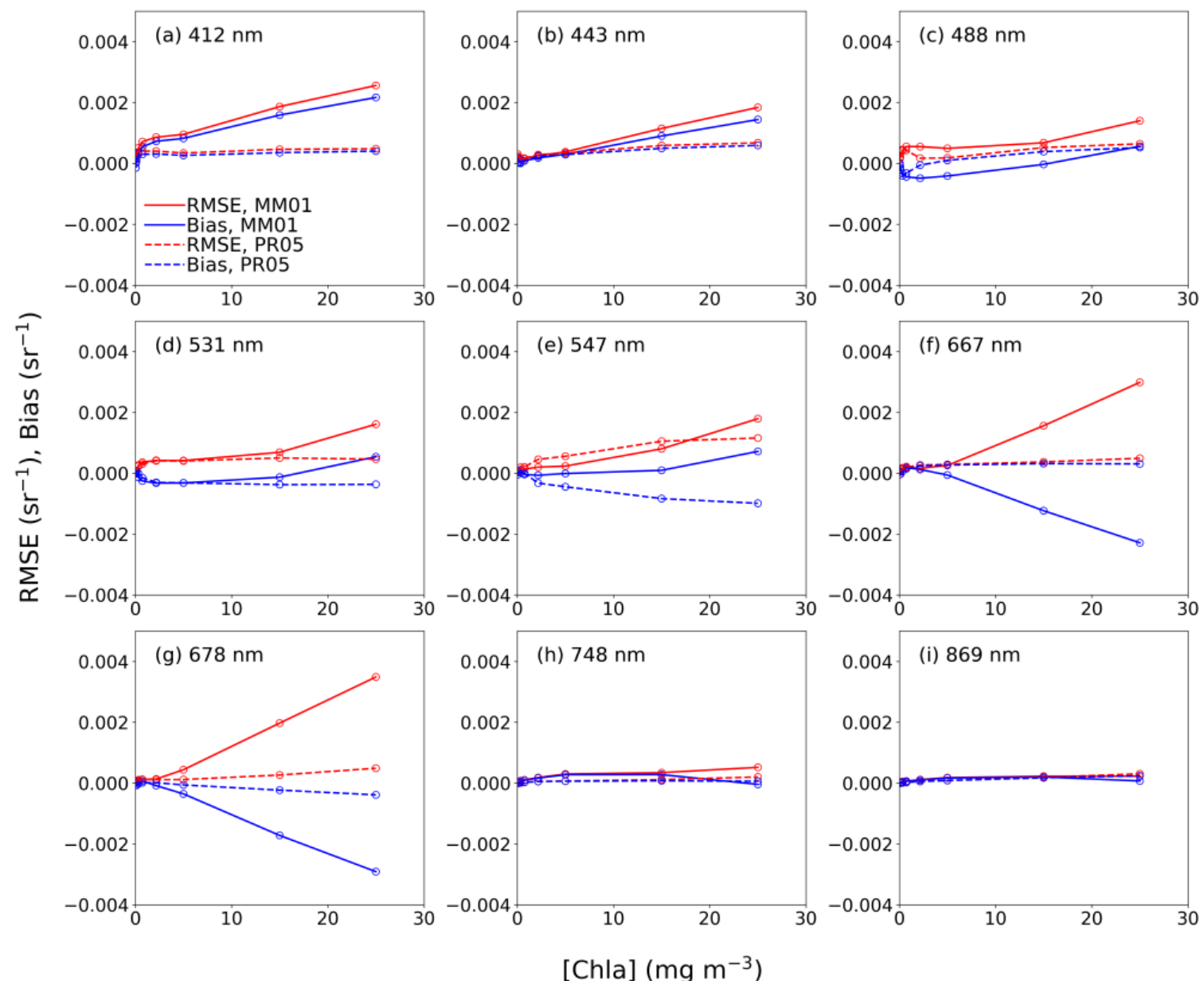

[Chla] $\left(\mathrm{mg} \mathrm{m}^{-3}\right)$

Figure 5. Bias and RMSE as a function of [Chla], based on MM01 and PR05 reconstructed results using Hydrolight simulations. Eight [Chla] bins were used and the number of points was identical for each bin.

The MM01 and PR05 reconstructed $R_{r s}$ were also used as input to the QAA algorithm [20] to retrieve IOPs including absorption of detritus and CDOM at $443 \mathrm{~nm}\left(a_{d g}(443)\right)$, phytoplankton absorption at $443 \mathrm{~nm}\left(a_{p h}(443)\right)$, and backscattering of particles at $547 \mathrm{~nm}\left(b_{b p}(547)\right)$. When using the Hydrolight simulated $R_{r s}$ as input to the QAA, the bias and RMSE for retrieved $a_{d g}(443), a_{p h}(443)$, and $b_{b p}(547)$ are $-3.3 \%$ and $29.3 \%,-3.4 \%$ and $34.4 \%$, and $-1.8 \%$ and $55.6 \%$, respectively (Figure $6 \mathrm{a}-\mathrm{c}$ ). These values quantify algorithm errors. When using the reconstructed $R_{\mathrm{rs}}$ as input, the retrieved $a_{d g}(443), a_{p h}(443)$, and $b_{b p}(443)$ are largely biased, i.e., bias being $-71.0 \%, 57.8 \%$, and $-23.7 \%$ for MM01, and $-31.3 \%,-11.4 \%$, and $-14.6 \%$ for PR05, when compared with the prescribed values (Figure $6 \mathrm{~d}-\mathrm{i}$ ). The errors of using the MM01 and PR05 reconstructed $R_{\mathrm{rs}}$ are much higher than those of using Hydrolight simulated $R_{\text {rs }}$. Specifically, the performance of using the PR05 reconstructed $R_{r s}$ is better than that of using the MM01 reconstructed $R_{r s}$ with relatively lower bias and RMSE. The QAA algorithm involves two important parameters: $u$ and $\chi$, the first one depending on $R_{\mathrm{rs}}$ values and the second one 
depending on $R_{\mathrm{rs}}$ ratios. The value of $b_{b p}(547)$ depends on $u$ at $547 \mathrm{~nm}, u(547)$, and the total absorption coefficient at $547 \mathrm{~nm}, a(547)$. Since $u(547)$ is related to $R_{r s}(547)$ only and $a(547)$ is related to the ratio $R_{r s}(443) / R_{r s}(547), R_{r s}(488) / R_{r s}(547)$, and $R_{r s}(667) / R_{r s}(547)$, it is expected that the retrieved $b_{b p}(547)$ values show larger bias and RMSE compared with the retrieval using the Hydrolight simulated $R_{r s}$, and the errors are larger for the MM01 model than for the PR05 model based on the model performance in reconstructing $R_{r s}(667)$ (Figure 3). The value of $a_{d g}(443)$ is expressed as a function of $b_{b p}(547), R_{r s}(412)$, $R_{r s}(443)$, and $R_{r s}(443) / R_{r s}(547)$. Therefore, the error in the $b_{b p}(547)$ propagates further and results in much larger error in the retrieved $a_{d g}(443)$, as shown in Figure $6 \mathrm{~d}, \mathrm{~g}$. Also, the retrieval error in $a_{d g}(443)$ is less when using the PR05 model reconstructed $R_{r s}$ due to the smaller error in $b_{b p}(547)$. The value of $a_{p h}(443)$ is calculated as the total absorption minus $a_{d g}$ and the absorption of pure sea water, in which way the error in retrieving $a_{p h}(443)$ is compensated to some extent as the total absorption is derived using $b_{b p}(547)$ and $R_{r s}(443)$. It is concluded that using successfully the QAA algorithm requires accurate input of $R_{r s}$ and $R_{r s}$ ratios. Other IOP algorithms such as GSM [43] and GIOP [44] also use $R_{r s}$ as input and may have similar problems. Therefore, the MM01 and PR05 reconstructed $R_{r s}$ should be used with caution to retrieve IOPs. One may envision, however, applying these inversion schemes to reflectance ratios, as long as sensitivity to IOPs remains adequate.
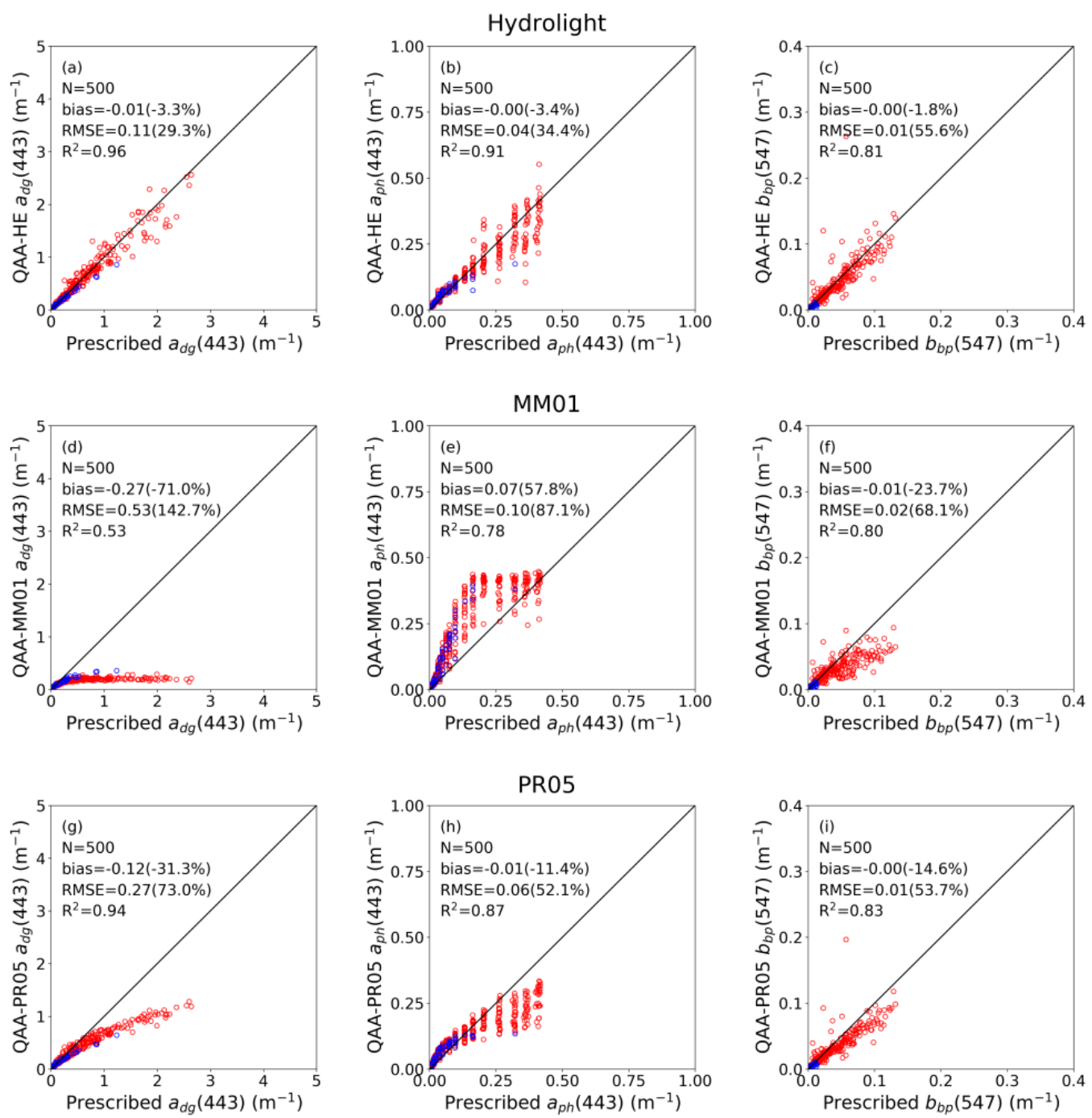

Figure 6. Comparison of QAA derived $a_{d g}(443), a_{p h}(443)$, and $b_{b p}(547)$ using Hydrolight simulated $R_{r s}(\mathbf{a}-\mathbf{c})$, MM01 reconstructed $R_{r s}(\mathbf{d}-\mathbf{f})$, and PR05 reconstructed $R_{r s}(\mathbf{g}-\mathbf{i})$ versus prescribed values. Blue circles represent Case 1 water and red represent Case 2 water. 
The three-parameter PR05 model was evaluated to figure out whether the $\mathrm{R}_{\mathrm{rs}}$ reconstruction would be improved by introducing more parameters (Table 3). Results show that by introducing the third parameter $f a$ (see Section 2.1), the PR05 model does improve the estimation of $R_{r s}$ at all wavelengths except $531 \mathrm{~nm}$, wavelength for which the bias and RMSE are slightly higher than using a two-parameter model. However, the improvement is not significant for 412, 443, 488, 547, and $667 \mathrm{~nm}$, with bias and RMSE reduced by about $1 \%$ or even less. Much more improvement is seen at longer wavelengths (i.e., 678, 748, and $869 \mathrm{~nm}$ ), but the differences between Hydrolight simulated and PR05 modeled $R_{r s}$ are still large, for example the RMSE at $869 \mathrm{~nm}$ is $0.00010 \mathrm{sr}^{-1}(56.1 \%)$. Similar results of $R_{r s}$ are observed when separating Case 1 and Case 2 waters. Therefore, having a more intricate model may not be warranted. The trade-off is between efficiency/robustness and accuracy. It also should be noted that having more input parameters in the spectral-matching scheme might not guarantee convergence. It is concluded that the PR05 model with two parameters is preferred for $R_{r s}$ estimation than the three-parameter model (allows faster and easier convergence while keeping similar accuracy).

Table 3. Performance statistics of three-parameter PR05 reconstructed $R_{r s}$ for Case 1 and Case 2 water using Hydrolight simulations.

\begin{tabular}{|c|c|c|c|c|c|c|c|c|c|}
\hline \multirow[b]{2}{*}{ Parameter } & \multicolumn{3}{|c|}{ Case $1, \mathrm{~N}=55$} & \multicolumn{3}{|c|}{ Case $2, \mathrm{~N}=445$} & \multicolumn{3}{|c|}{ All Cases, $\mathbf{N}=500$} \\
\hline & $\mathbf{R}^{2}$ & $\begin{array}{c}\text { Bias, } 1^{-3} \\
\text { sr }^{-1}(\text { bias } \%)\end{array}$ & $\begin{array}{c}\text { RMSE, 10-3 } \\
\text { sr }^{-1} \text { (RMSE\%) }\end{array}$ & $\mathbf{R}^{2}$ & $\begin{array}{c}\text { Bias, } 1^{-3} \\
\text { sr }^{-1}(\text { bias } \%)^{2}\end{array}$ & $\begin{array}{c}\text { RMSE, 10-3 } \\
\text { sr }^{-1} \text { (RMSE\%) }\end{array}$ & $\mathbf{R}^{2}$ & $\begin{array}{c}\text { Bias, } 1^{-3} \\
\text { sr }^{-1}(\text { bias } \%)^{2}\end{array}$ & $\begin{array}{c}\text { RMSE, 10-3 } \\
\text { sr-1 }^{-1}(\text { RMSE } \%)^{2}\end{array}$ \\
\hline$R_{r s}(412)$ & 1.00 & $0.05(1.7)$ & $0.07(2.4)$ & 1.00 & $0.25(4.9)$ & $0.36(6.9)$ & 1.00 & $0.23(4.7)$ & $0.34(6.8)$ \\
\hline$R_{r s}(488)$ & 1.00 & $-0.05(-1.7)$ & $0.08(2.8)$ & 0.98 & $-0.02(-0.3)$ & $0.36(5.8)$ & 0.99 & $-0.02(-0.3)$ & $0.34(5.8)$ \\
\hline$R_{r s}(531)$ & 0.99 & $-0.03(-1.2)$ & $0.07(2.7)$ & 1.00 & $-0.20(-3.1)$ & $0.36(5.7)$ & 1.00 & $-0.18(-3.1)$ & $0.34(5.8)$ \\
\hline$R_{r s}(547)$ & 0.99 & $-0.01(-0.3)$ & $0.07(2.8)$ & 0.99 & $-0.34(-5.2)$ & $0.63(9.5)$ & 0.99 & $-0.31(-4.9)$ & $0.59(9.6)$ \\
\hline$R_{r s}(748)$ & 0.98 & $0.02(25.9)$ & $0.03(41.4)$ & 0.99 & $0.01(2.2)$ & $0.07(16.1)$ & 0.99 & $0.01(2.6)$ & $0.07(17.0)$ \\
\hline$R_{r s}(869)$ & 0.96 & $0.02(57.9)$ & $0.03(92.0)$ & 0.99 & $0.07(32.7)$ & $0.11(53.6)$ & 0.99 & $0.06(33.1)$ & $0.10(56.1)$ \\
\hline
\end{tabular}

\subsection{Sensivity of $R_{r s}$ Reconstruction to Atmospheric Transmittance}

In the POLYMER algorithm, the TOA reflectance is decomposed as follows [13]:

$$
\rho_{T O A}(\lambda)=t_{o z}(\lambda)\left[\rho_{m o l}(\lambda)+T(\lambda) \rho_{g l i}(\lambda)+\rho_{a e r}(\lambda)+\rho_{g a m}(\lambda)+t(\lambda) \rho_{w}(\lambda, 0+)\right]
$$

where $t_{o z}(\lambda)$ is the ozone transmittance, $\rho_{\text {mol }}(\lambda)$ is the Rayleigh scattering reflectance, $\rho_{g l i}(\lambda)$ is the (non-spectral) sun glint reflectance affected by the direct transmission factor $T(\lambda), \rho_{a e r}(\lambda)$ is the aerosol reflectance, $\rho_{\text {gam }}(\lambda)$ accounts for the coupling between Fresnel reflectance and scattering by molecules and aerosols, $t(\lambda)$ is the total (i.e., direct + diffuse) transmittance for atmospheric scattering, and $\rho_{w}(\lambda, 0+)$ is the water reflectance above the water-air interface $\left(\rho_{w}=\pi R_{r s}\right)$. In this decomposition, the atmosphere is assumed to be clear (i.e., no clouds). In the presence of clouds, Equation (2) should be modified to account for scattering by cloud droplets and its interaction with molecule/aerosol scattering and surface reflection, and $t(\lambda)$ should include cloud transmittance, i.e., $t(\lambda)=t_{m o l}(\lambda) t_{\text {aer }}(\lambda) t_{\text {cloud }}(\lambda)$, where subscripts mol, aer, and cloud refer to molecules, aerosols, and clouds, The transmittance $t(\lambda)$ is pre-calculated with a successive orders of scattering (SOS) code [45] and stored in look-up tables, but only molecules are considered in the calculations, even though the algorithm is designed to work in the presence of aerosols and, at least, optically thin clouds. Neglecting the transmittance of aerosols and clouds is expected to affect the $R_{r s}$ reconstruction in the spectral-matching scheme. Therefore, it is important to evaluate the sensitivity of the $R_{r s}$ reconstruction using the MM01 and PR05 models to cloud and aerosol transmittance.

To perform such evaluation, the aerosol total transmittance $t_{\text {aer }}$ was modeled following Tanre et al. [46]:

$$
t_{\text {aer }}=\exp \left[-0.16 \tau_{\text {aer }}(\lambda)\left(1 / \cos \left(\theta_{v}\right)+1 / \cos \left(\theta_{s}\right)\right)\right],
$$


where $\theta_{s}$ and $\theta_{v}$ are the Sun and view zenith angles, respectively, and $\tau_{a e r}$ is the aerosol optical thickness, $\tau_{\text {aer }}(\lambda)=0.1(\lambda / 865)^{-1}$. The cloud transmittance $t_{\text {cloud }}$ was parameterized according to Fitzpatrick et al. [47]:

$$
\begin{gathered}
t_{\text {cloud }}=\left[a(\tau)+b\left(\tau_{\text {cloud }}\right) \cos \theta_{v}\right]\left[a(\tau)+b\left(\tau_{\text {cloud }}\right) \cos \theta_{s}\right] /\left[1+(c-d \alpha) \tau_{\text {cloud }}\right]^{2}, \\
a(\tau)=a_{1}+\left(1-a_{1}\right) \exp \left(-k_{1} \tau_{\text {cloud }}\right), \\
b(\tau)=b_{1}\left[1+b_{2} \exp \left(-k_{2} \tau_{\text {cloud }}\right)+b_{3} \exp \left(-k_{3} \tau_{\text {cloud }}\right)\right],
\end{gathered}
$$

where $\tau_{\text {cloud }}$ is geometric-optics cloud optical thickness, $\alpha$ is surface albedo. Cloud optical depth $\tau_{\text {cloud }}$ is set to 3 (thin cloud), and surface albedo $\alpha$ to 0.06 . Sun and view zenith angles are those of the IOCCG dataset, i.e., $30^{\circ}$ and $0^{\circ}$, respectively. The coefficients $a_{1}, b_{1}, b_{2}, b_{3}, k_{1}, k_{2}, k_{3}, c$, and $d$ are tabulated in Fitzpatrick et al. [47] as a function of wavelength. The resulting $t_{\text {cloud }}$ values were interpolated to the MODIS wavelengths. With the calculated $t_{a e r}$ and $t_{\text {cloud }}$, the Hydrolight simulated $R_{r s}$ were transformed to $R_{r s} t_{a e r} t_{c l o u d}$, and the MM01 and PR05 model parameters were retrieved using $R_{r s} t_{a e r} t_{c l o u d}$ instead of $R_{r s}$ as input.

Figures 7 and 8 display the resulting scatter plots of MM01 and PR05 reconstructed $R_{r s}$, [Chla], and $R_{r s}$ ratios versus the Hydrolight simulations. The reconstructed $R_{r s}$ is systematically biased, i.e., by $20-40 \%$, after taking into account the cloud and aerosol transmittance. However, the $R_{r s}$ ratios are still in good agreement with the Hydrolight simulated ratios, i.e., they exhibit bias and RMSE comparable to those obtained without considering the effects of transmittance. When using the MM01 and PR05 reconstructed $R_{r s}$ to estimate [Chla] with the OCI algorithm, the resulting bias and RMSE increase to 0.039 (32.5\%) and $0.040 \mathrm{mgm}^{-3}(33.1 \%)$, and $0.036(29.9 \%)$ and $0.036 \mathrm{mgm}^{-3}(30.5 \%)$, respectively. This is because the cloud and aerosol transmittances introduce a large bias, i.e., more than $20 \%$, to $R_{r s}$, which is further propagated to the CI index. The cloud and aerosol transmittances do not have much effect on the model-retrieved [Chla]; statistics are similar to those in Figure 4. However, again for both models, the Nelder-Mead [Chla] does not represent well the actual values. Note that most of the impact on the $R_{r s}$ reconstruction performance is due cloud transmittance $(0.78$ at $443 \mathrm{~nm})$, as the aerosol transmittance ( 0.95 at $443 \mathrm{~nm})$ is close to 1 .
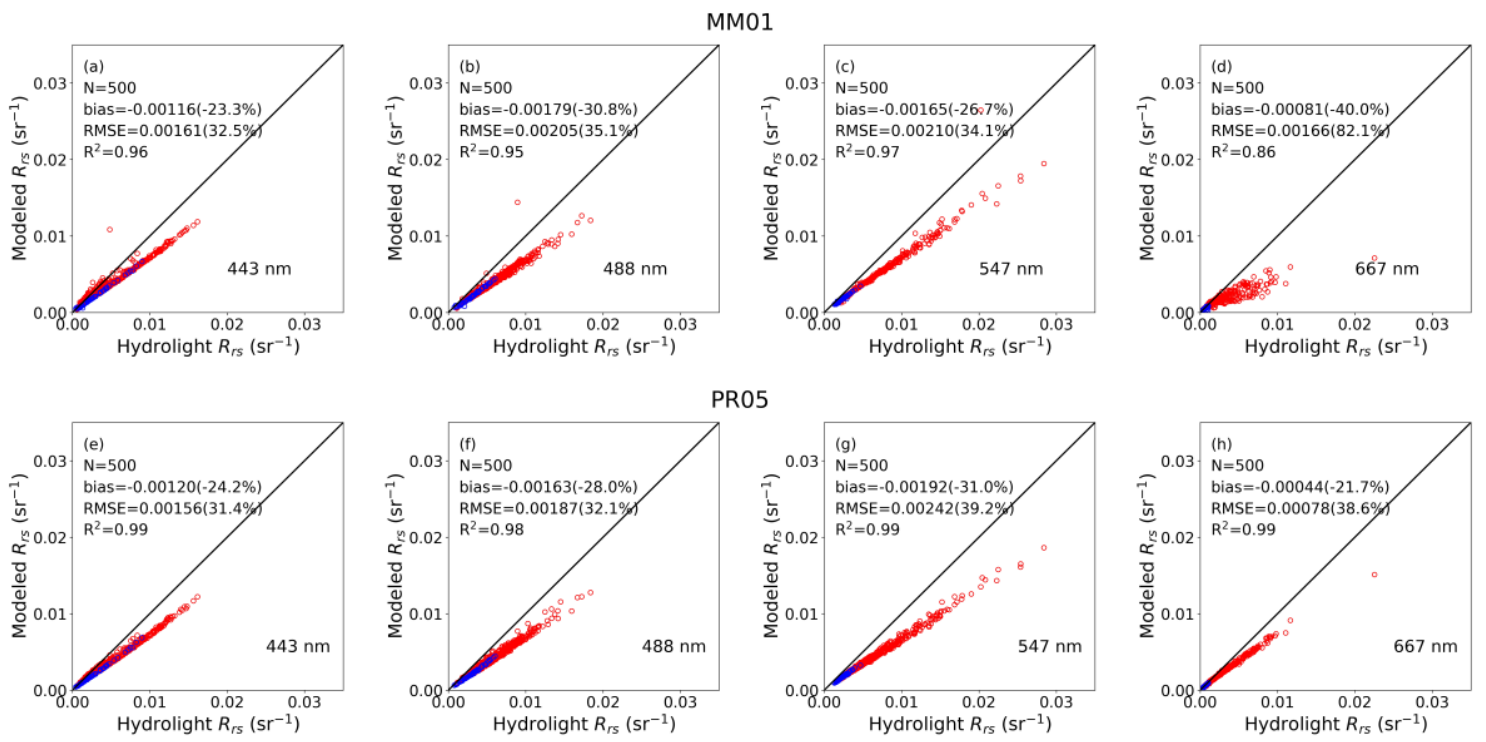

Figure 7. Comparison of the MM01 (a-d) and PR05 (e-h) reconstructed remote sensing reflectance $R_{r s}$ with Hydrolight simulated $R_{r s}$ at selected MODIS wavelengths $(443,488,547$, and $667 \mathrm{~nm}$ ), after applying cloud and aerosol transmittance. Blue circles represent Case 1 water and red represent Case 2 water. 

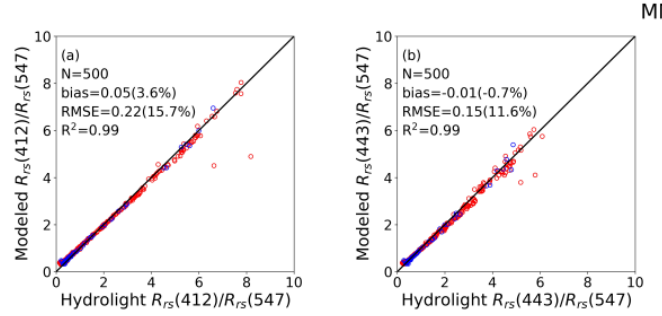

MM01
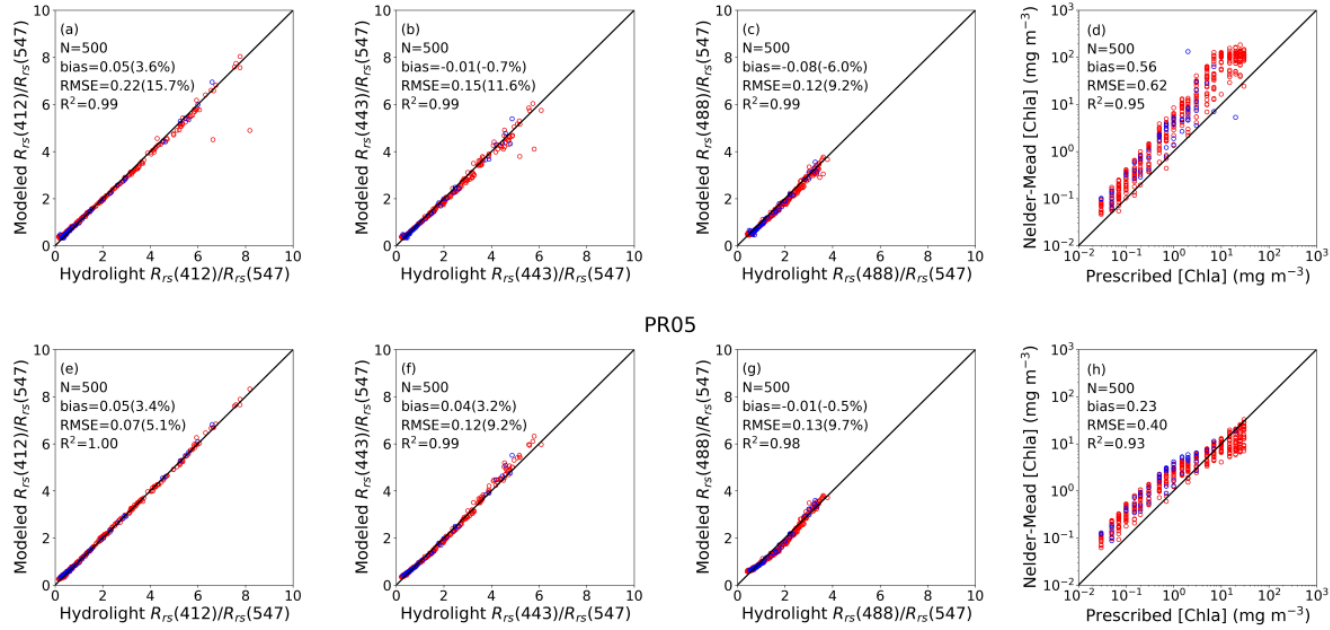

PR05

Figure 8. Comparison of the MM01 (a-d) and PR05 (e-h) reconstructed versus Hydrolight simulated band ratios $R_{r s}(412) / R_{r s}(547), R_{r s}(443) / R_{r s}(547)$, and $R_{r s}(488) / R_{r s}(547)$, as well as Nelder-Mead retrieved versus prescribed [Chla], after applying the cloud and aerosol transmittance. Blue circles represent Case 1 water and red represent Case 2 water. The bias and RMSE of [Chla] were calculated on log10 scale.

When using the reconstructed $R_{r s}$ as input to the QAA algorithm to retrieve $a_{d g}(443), a_{p h}(443)$, and $b_{b p}(547)$, large errors are obtained compared with the results using the Hydrolight simulated reflectance spectra (Figure 9). As discussed in Section 3.1, the retrieved value of $b_{b p}(547)$ is dependent on $R_{r s}(547), R_{r s}(443) / R_{r s}(547), R_{r s}(488) / R_{r s}(547)$, and $R_{r s}(667) / R_{r s}(547)$. Since the reconstructed $R_{r s}(547)$ is systematically biased when the effects of aerosol/cloud transmittance are taken into account (Figure 7), and even though the values of $R_{r s}(443) / R_{r s}(547), R_{r s}(488) / R_{r s}(547)$, and $R_{r s}(667) / R_{r s}(547)$ (Figure 8) are similar to those with no transmittance, the error in the retrieved $b_{b p}(547)$ is increased (compare Figure 9 with Figure 6). However, since $a_{d g}(443)$ and $a_{p h}(443)$ are not only determined by $b_{b p}(547)$ but also by $R_{r s}(412), R_{r s}(443)$, and $R_{r s}(443) / R_{r s}(547)$, in the end the errors somewhat compensate, yielding bias and RMSE for $a_{d g}(443)$ and $a_{p h}(443)$ that are similar to those before accounting for aerosol/cloud transmittance. Again, the errors in the retrieved IOPs are less when using the PR05 model reconstructed $R_{r s}$, compared with the MM01 results.
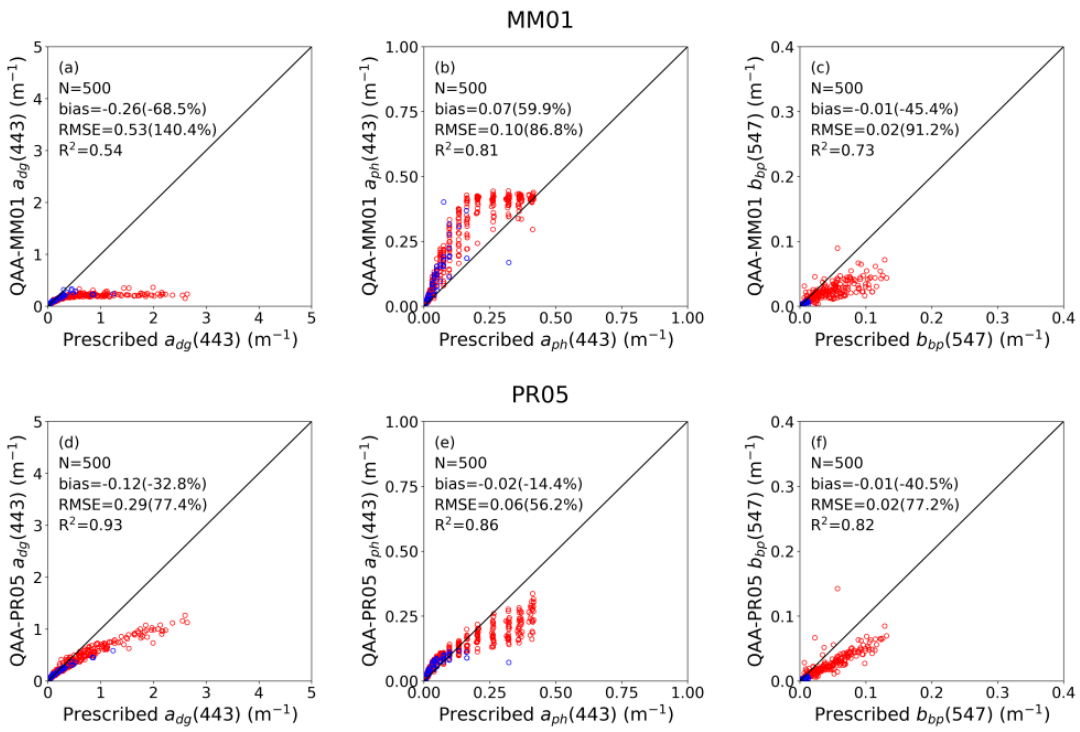

Figure 9. Comparison of QAA derived $a_{d g}(443), a_{p h}(443)$, and $b_{b p}(547)$ using MM01 reconstructed $R_{r s}$ $(\mathbf{a}-\mathbf{c})$ and PR05 reconstructed $R_{r s}(\mathbf{d}-\mathbf{f})$ versus prescribed values, after applying cloud and aerosol transmittance. Blue circles represent Case 1 water and red represent Case 2 water. 


\subsection{Model Performance Using AERONET-OC Dataset}

Model (MM01, PR05) performance was further evaluated using the AERONET-OC dataset. The AERONET-OC dataset does not include $R_{r s}$ at all wavelengths, i.e., only $R_{r s}$ at $412,443,488$, $531,547,667$, and $869 \mathrm{~nm}$ are available. To determine if missing $R_{r s}$ at 678 and $748 \mathrm{~nm}$ affects the model performance, tests were made using the 500 Hydrolight simulated cases (Section 2.3) with full MODIS wavelengths and with partial MODIS wavelengths (excluding 678 and $748 \mathrm{~nm}$ ). No significant difference (i.e., less than $1 \%$ ) in bias and RMSE was observed between $R_{r s}$, [Chla], and $R_{r s}$ ratios retrieved using the full or partial set of wavelengths. Therefore, the errors caused by missing wavelengths are regarded as negligible in the following study. Prior to evaluation, Case 1 and Case 2 water situations were separated by using the same criteria that were applied to the Hydrolight simulations, taking the solar zenith angle into account. This resulted in 6094 Case 1 water and 3730 Case 2 water situations (Figure 10).
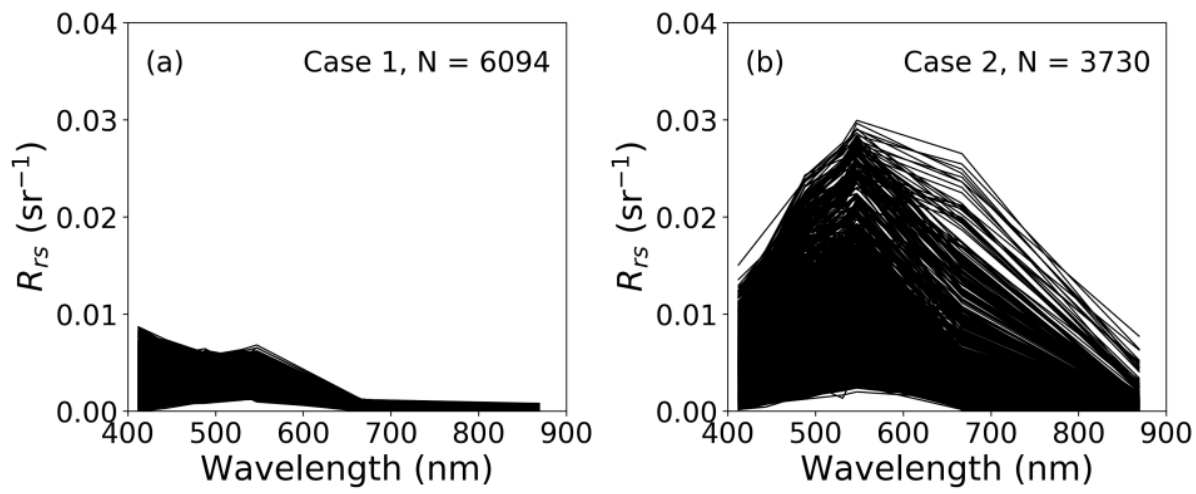

Figure 10. AERONET-OC spectra of remote sensing reflectance $R_{r s}$ of Case 1 (a) and Case 2 (b) waters. To distinguish Case 1 and 2 water situations, two thresholds were used: the threshold of Morel and Bélanger [32], i.e., the limiting $R_{w}(560)$ values produced by the bio-optical model of Morel and Maritorena [13] with the upper limit of $b_{p}(560)=0.69[\mathrm{Chla}]^{0.766}$ as input, and the threshold of Robinson et al. [33], i.e. $R_{r s}(670) \leq 0.0012 \mathrm{sr}^{-1}$ for Case 1 water, otherwise Case 2 water.

As shown in Figure 11, top and Table 4, the MM01 model performs generally well in reconstructing $R_{\mathrm{rs}}$ at 443,488 , and $547 \mathrm{~nm}$. The bias and RMSE values are $-0.00001(-0.2 \%)$ and $0.00032 \mathrm{sr}^{-1}(9.2 \%)$, $-0.00055(-11.7 \%)$ and $0.00085 \mathrm{sr}^{-1}(18.0 \%), 0.00025(5.5 \%)$ and $0.00056 \mathrm{sr}^{-1}(12.2 \%)$ respectively, i.e., higher than those obtained using Hydrolight simulations. Much larger bias and RMSE are found at $667 \mathrm{~nm}$, which are $-0.00015(-12.1 \%)$ and $0.0010 \mathrm{sr}^{-1}(84.5 \%)$, respectively. Nevertheless, the errors in $R_{\mathrm{rs}}$ are still smaller than typical POLYMER atmospheric correction errors. The PR05 model performs better in reconstructing $R_{\mathrm{rs}}$ with generally lower bias and RMSE at each wavelength (Figure 11, bottom, and Table 4). Unlike for the MM01 model, the PR05 reconstructed $R_{r s}$ values at $667 \mathrm{~nm}$ are in good agreement with the AERONET-OC measurements, even though fluorescence is not considered in the PR05 model. Similar to the MM01 results, the bias and RMSE values of the PR05 reconstruction are higher than those obtained using Hydrolight simulations. As discussed in the previous section, the simplified representation of the backscattering of non-algal particles, together with the lack of consideration of fluorescence and CDOM and non-algal absorption in the MM01 model are the main contributors to the errors in reconstructed $R_{r s}$. The PR05 model takes into account the absorption and backscattering of non-algal particles by using the [Chla] and $f b$ parameters, but the slope used for CDOM absorption might not be sufficiently well representative, causing substantial errors at $547 \mathrm{~nm}$ for Case 2 water situations when applying the spectral-matching scheme for inversion. Note that the Hydrolight simulated $R_{r s}$ is not subjected to radiometric errors and other, e.g., environmental, perturbations and this may partly explain why the bias and RMSE in reconstructed $R_{r s}$ using the AERONET-OC dataset are larger than those obtained using Hydrolight simulations. 

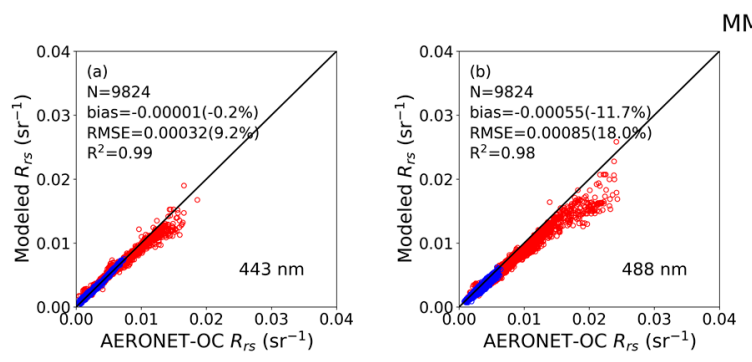

MM01
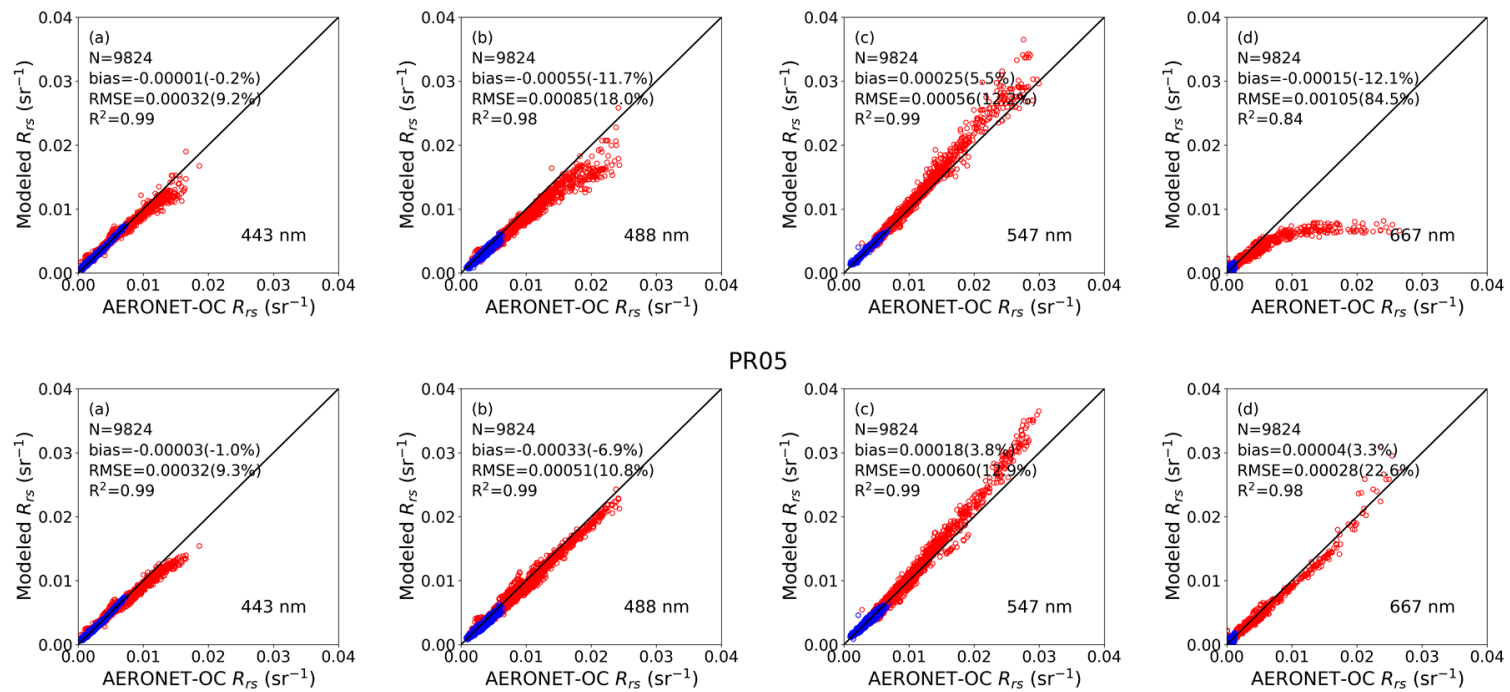

Figure 11. Comparison of MM01 (a-d) and PR05 (e-h) reconstructed remote sensing reflectance $R_{r s}$ with AERNOET-OC $R_{r s}$ at selected MODIS wavelengths: $443 \mathrm{~nm}, 488 \mathrm{~nm}, 547 \mathrm{~nm}$, and $667 \mathrm{~nm}$. Blue circles represent Case 1 water and red represent Case 2 water.

Table 4. Performance statistics of MM01 and PR05 reconstructed $R_{r s}$ for Case 1 and Case 2 water using AERONET-OC dataset.

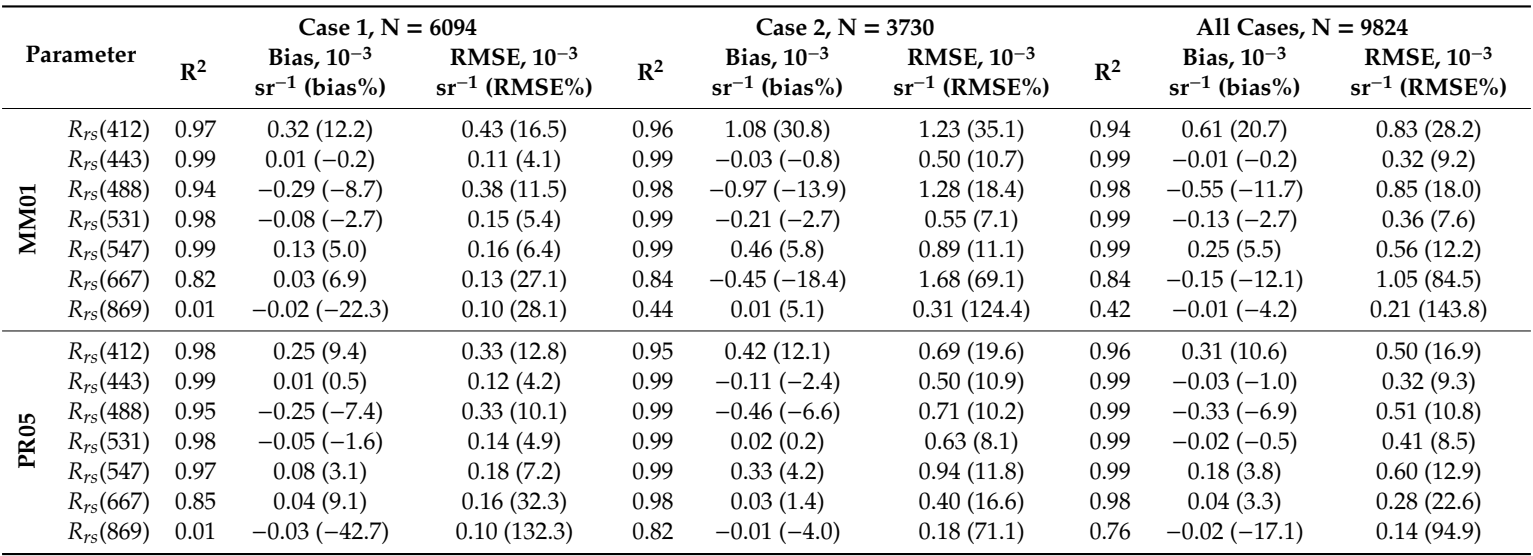

Figure 12 displays scatter plots of the model reconstructed and AERONET-OC measured $R_{r s}$ ratios. Results show that the MM01 and PR05 band ratios $R_{r s}(412) / R_{r s}(547), R_{r s}(443) / R_{r s}(547)$, and $R_{r s}(488) / R_{r s}(547)$ are all in good agreement with the AERONET-OC measurements. The overall bias is less than 15\% and the overall RMSE less than 18\% for the MM01 model. The PR05 reconstruction gives slightly better results, with the overall bias less than $11 \%$ and the overall RMSE less than $16 \%$. As expected, the errors in the reconstructed $R_{r s}$ ratios are larger than those obtained using Hydrolight simulations. Table 5 shows that the model reconstructed $R_{r s}$ ratios agree well with the prescribed values for both Case 1 and Case 2 waters, with errors slightly lower for Case 1 situations than for Case 2 situations. When applying the MM01 and PR05 reconstructed $R_{r s}$ to estimate [Chla] using the OCI algorithm, the resulting bias and RMSE for [Chla] are $0.010(4.8 \%)$ and $0.014 \mathrm{mgm}^{-3}(6.8 \%)$, and $0.007(3.6 \%)$ and $0.011 \mathrm{mgm}^{-3}(5.4 \%)$, respectively. This confirms that both the MM01 and PR05 reconstructed $R_{r s}$ can be used to estimate [Chla] using band ratio and $\mathrm{OCI}$ algorithms. Figure 12 also shows that the model-retrieved [Chla] differs substantially from the AERONET-OC [Chla], both models tending to overestimate [Chla]. However, for both models the overall agreement is better than when using Hydrolight simulations: the bias and RMSE on $\log 10$ scale are 0.33 and 0.42 instead of 0.52 and 0.60 , respectively, for the MM01 model, and 0.12 and 0.23 instead of 0.21 and 0.37 , respectively, 
for the PR05 model. The statistics are similar when Case 1 and Case 2 waters are used separately (Table 5). The comparisons suggest that the bio-optical relationships used in both models, based on field measurements, are more representative of actual situations than those in the Hydrolight simulations. Despite the improvement in [Chla] estimate, the model-retrieved [Chla] should still not be considered as representative of the actual [Chla].
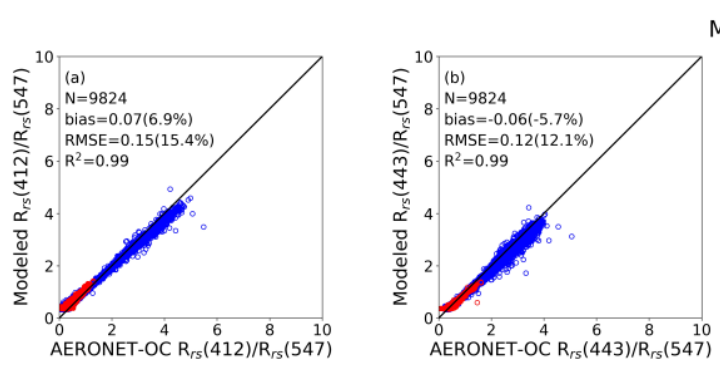

MM01
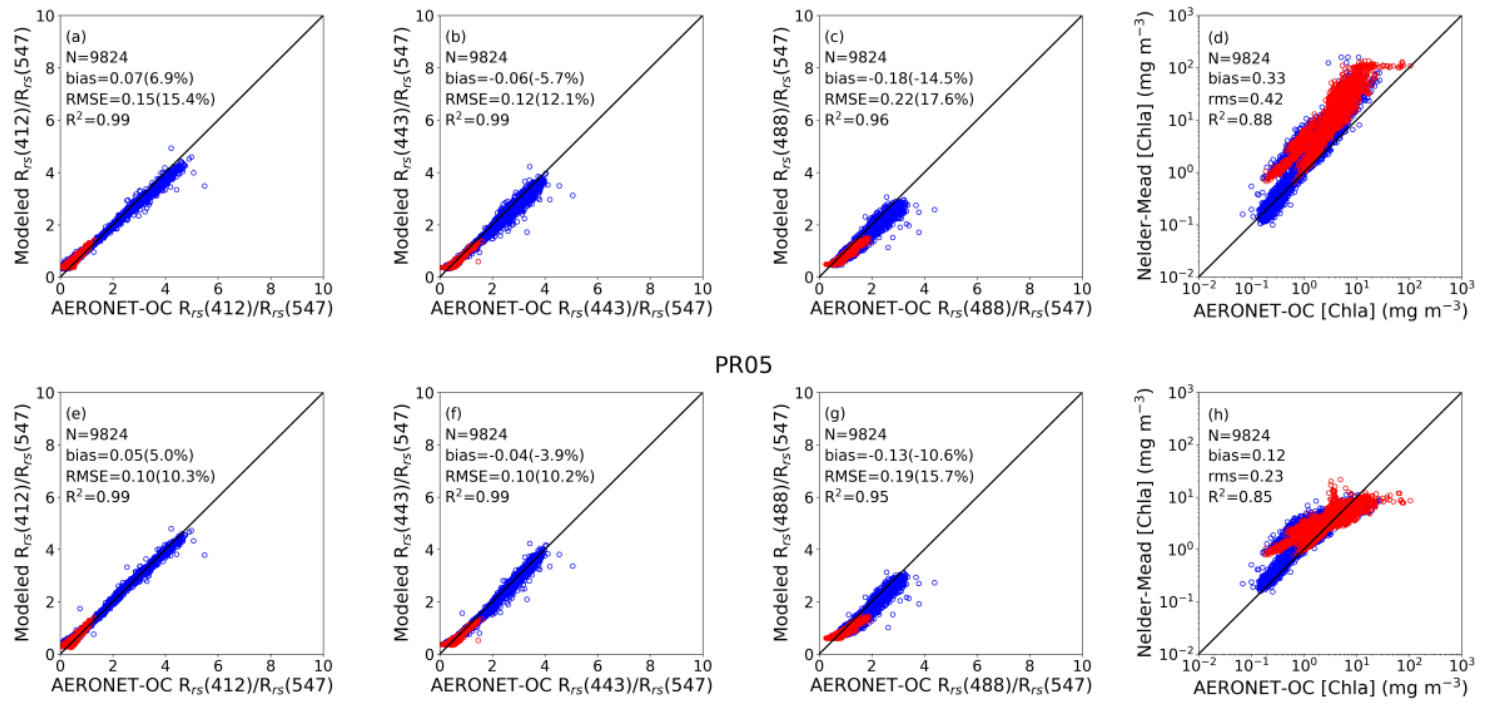

PR05
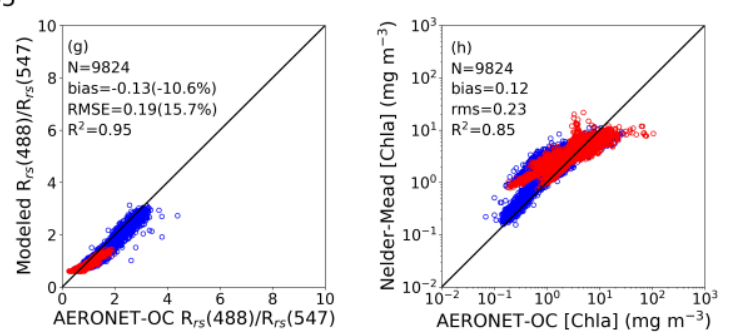

Figure 12. Comparison of the MM01 (a-d) and PR05 (e-h) reconstructed versus AERONET-OC measured band ratios $R_{r s}(412) / R_{r s}(547), R_{r s}(443) / R_{r s}(547)$, and $R_{r s}(488) / R_{r s}(547)$, as well as Nelder-Mead retrieved versus prescribed [Chla]. Blue circles represent Case 1 water and red represent Case 2 water. The bias and RMSE of [Chla] were calculated on $\log 10$ scale.

Table 5. Performance statistics of MM01 and PR05 reconstructed $R_{r S}$ ratios and log10([Chla]) for Case 1 and Case 2 water using AERONET-OC dataset. The bias and RMSE of log10([Chla]) are in the unit of $\mathrm{mg} \mathrm{m} \mathrm{m}^{-3}$.

\begin{tabular}{|c|c|c|c|c|c|c|c|}
\hline & \multirow[b]{2}{*}{ Parameter } & \multicolumn{3}{|c|}{ Case $1, N=6094$} & \multicolumn{3}{|c|}{ Case $2, \mathrm{~N}=3730$} \\
\hline & & $\mathbf{R}^{2}$ & Bias (bias\%) & RMSE (RMSE\%) & $\mathbf{R}^{2}$ & Bias (bias\%) & RMSE (RMSE\%) \\
\hline \multirow{4}{*}{$\sum_{\Sigma}^{\sigma}$} & $R_{r s}(412) / R_{r s}(547)$ & 0.99 & $0.03(2.4)$ & $0.15(11.8)$ & 0.87 & $0.12(28.7)$ & $0.14(32.6)$ \\
\hline & $R_{r s}(443) / R_{r s}(547)$ & 0.99 & $-0.08(-6.0)$ & $0.15(11.4)$ & 0.94 & $-0.02(-3.5)$ & $0.06(11.0)$ \\
\hline & $R_{r s}(488) / R_{r s}(547)$ & 0.96 & $-0.19(-13.1)$ & $0.24(16.4)$ & 0.89 & $-0.16(-18.2)$ & $0.18(20.4)$ \\
\hline & $\log _{10}([$ Chla $])$ & 0.88 & 0.22 & 0.33 & 0.80 & 0.50 & 0.54 \\
\hline \multirow{4}{*}{$\begin{array}{l}\stackrel{2}{\circ} \\
\stackrel{2}{a}\end{array}$} & $R_{r s}(412) / R_{r s}(547)$ & 0.99 & $0.04(3.3)$ & $0.10(8.0)$ & 0.85 & $0.06(13.1)$ & $0.09(21.1)$ \\
\hline & $R_{r s}(443) / R_{r s}(547)$ & 0.99 & $-0.05(-4.1)$ & $0.12(9.1)$ & 0.91 & $-0.02(-3.1)$ & $0.08(13.5)$ \\
\hline & $R_{r s}(488) / R_{r s}(547)$ & 0.95 & $-0.16(-10.9)$ & $0.22(15.2)$ & 0.84 & $-0.08(-9.8)$ & $0.14(15.9)$ \\
\hline & $\log _{10}([\mathrm{Chla}])$ & 0.85 & 0.14 & 0.23 & 0.73 & 0.09 & 0.22 \\
\hline
\end{tabular}

When using the MM01 model for $R_{r s}$ reconstruction, relatively large bias and RMSE are observed at $488 \mathrm{~nm}$ (when [Chla] is within 2-4 $\mathrm{mg} \mathrm{m}^{-3}$ ) and $667 \mathrm{~nm}$ (when [Chla] is larger than $2 \mathrm{mg} \mathrm{m}^{-3}$ ) (Figure 13). Such behavior could be due to the fact that the absorption and backscattering of non-algal particles, fluorescence, and CDOM absorption are not taken into account in the MM01 model. For other wavelengths the bias and RMSE are relatively small and do not quite change with [Chla], except when [Chla] is within $2-4 \mathrm{mg} \mathrm{m}^{-3}$ (small increase). This is also the case when using PR05 model. This increased bias and RMS when [Chla] is in the range $2-4 \mathrm{mg} \mathrm{m}^{-3}$ could be due to the fact that the AERONET-OC [Chla] are not measured but estimated from remote sensing reflectance [19], and that higher uncertainty exists in this [Chla] range. It is also possible the variability of chlorophyll- $a$ absorption is not sufficiently well represented in the MM01 and PR05 model. The bias and RMSE are smaller over the entire 
[Chla] range when using the PR05 model, indicating the overall better performance of that model in reconstructing water reflectance, again confirming the results from simulations.

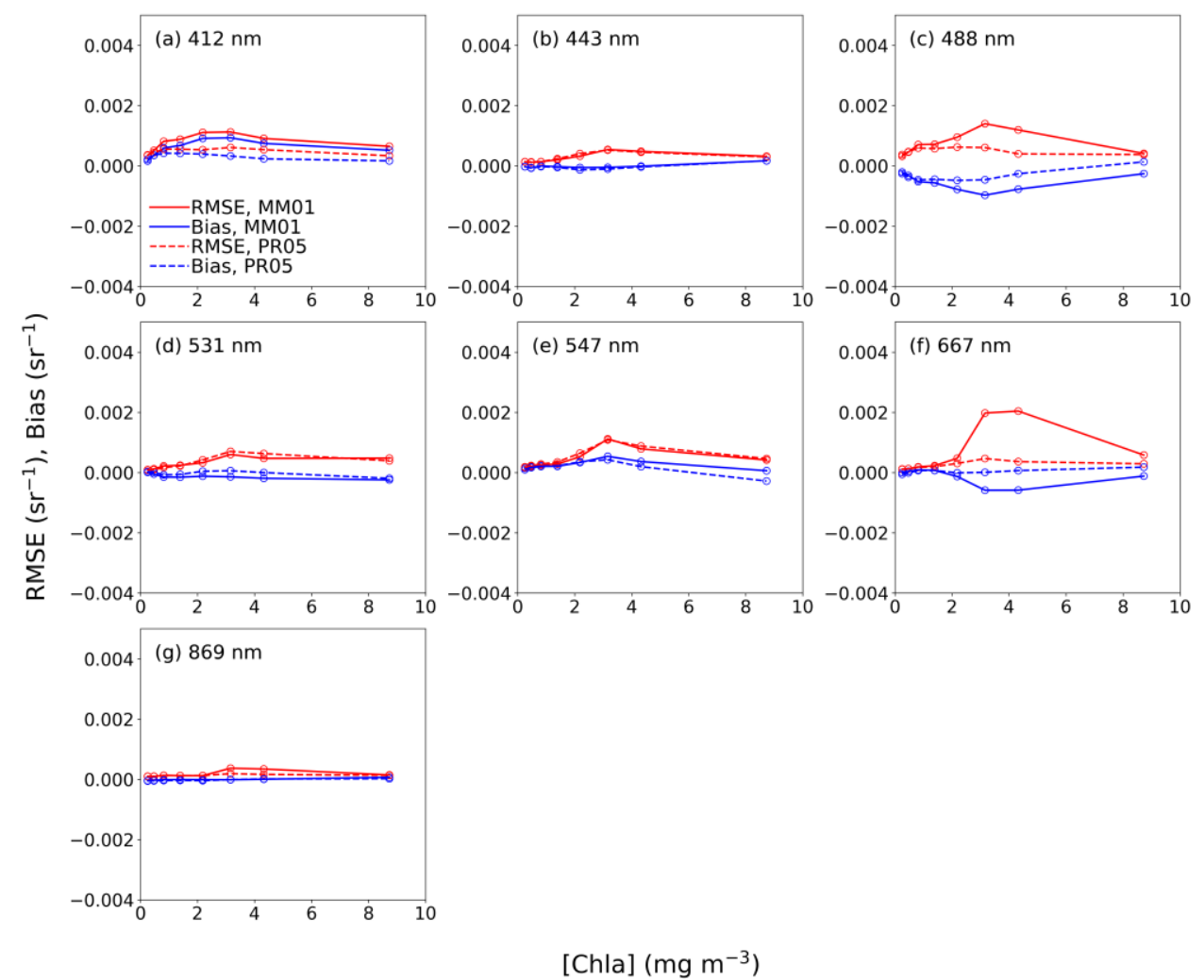

Figure 13. Bias and RMSE as a function of [Chla], based on MM01 and PR05 reconstructed results using AERONET-OC dataset. Eight [Chla] bins were used and the number of points was identical for each bin.

\section{Summary and Conclusions}

The MM01 and PR05 models used in the POLYMER spectral-matching algorithm have been examined in terms of their ability to properly represent water reflectance over the wide range of situations/regimes expected in oceans. The MM01 model, in the modified version considered, depends on chlorophyll-a concentration and backscattering coefficient for non-algal particles. The PR05 model depends on chlorophyll-a concentration, a parameter specifying the contribution of algal and non-algal particles to the backscattering coefficient, and a parameter allowing different absorption coefficients for dissolved organic matter. The two models have been evaluated separately for Case 1 and Case 2 waters at MODIS wavelengths (412, 443, 488, 531, 547, 667, 678, 748, and $869 \mathrm{~nm})$.

A theoretical evaluation was first performed using Hydrolight simulations with IOPs from an IOCCG synthesized dataset (500 cases) representing a wide range of field observations. Results show that the MM01 model generally performs well in retrieving $R_{r s}$ at 412, 443, 488, 531, and $547 \mathrm{~nm}$, even in optically complex waters. Neglecting CDOM absorption in the MM01 model is responsible for the relatively large bias and RMS found at $412 \mathrm{~nm}$. The discrepancies found at 667 and $869 \mathrm{~nm}$ for Case 2 water are mainly due to the backscattering of inorganic particles not well represented in the MM01 model. Other factors, including compensation by the spectral-matching scheme of differences at shorter wavelengths caused by the lack of CDOM and non-algal absorption and $R_{r s}$ extrapolation above $700 \mathrm{~nm}$ using the similarity spectrum, may also contribute to degradation of performance at 667 and $869 \mathrm{~nm}$. Despite the errors in $R_{r s}$, the MM01 retrieved $R_{r s}$ ratios are in very good agreement with the Hydrolight $R_{r s}$ ratios. The PR05 model, on the other hand, shows better performance than the MM01 model in reconstructing $R_{r s}$. The PR05 retrieved $R_{r s}$ values, obtained by fixing to unity 
the parameter allowing variable absorption by dissolved organic matter, agree with the Hydrolight values for both Case 1 and Case 2 situations at all visible wavelengths including 667 and $678 \mathrm{~nm}$, even though fluorescence is not considered in the model. The relatively large bias and RMSE at $547 \mathrm{~nm}$ is due to the non-representative slope of CDOM absorption and the spectral-matching scheme that minimizes the overall difference. Large discrepancy with the Hydrolight $R_{r s}$ values is found at 748 and $869 \mathrm{~nm}$, which reflects the generally lower $R_{r s}$, especially at $869 \mathrm{~nm}$, and could be partly due to the fact that the input absorption and scattering coefficients at these wavelengths are extrapolated from values at $700 \mathrm{~nm}$ instead of based on field measurements. Overall, the performance for Case 1 waters is better than that of for Case 2 waters. The PR05 reconstructed $R_{r s}$ ratios also agree well with the Hydrolight ratios. The reconstructed $R_{r s}$ from both models, when used in the OCI algorithm for oligotrophic waters, yields an accurate estimation of chlorophyll- $a$ concentration. However, the MM01 and PR05 retrieved $R_{r s}$, when used as input to the QAA algorithm, gives significant errors in the estimation of $a_{p h}(443), a_{d g}(443)$, and $b_{b p}(547)$. This is due to the fact that the QAA algorithm uses $R_{r s}$ at all visible wavelengths and not only $R_{r s}$ ratios. Therefore, caution should be exercised when using the model-retrieved $R_{r s}$ in algorithms for IOP estimations such as QAA. Importantly, the model parameters that best fit the input data, in particular chlorophyll- $a$ concentration, may not represent adequately actual values. The impact of cloud and aerosol transmittance (assumed to be 1 in POLYMER) on $R_{r s}$ reconstruction was also evaluated theoretically using Hydrolight simulations. While the cloud and aerosol transmittances do not affect significantly the reconstruction of $R_{r s}$ ratios, they do affect the accuracy of reconstructed $R_{r s}$, the OCI estimated chlorophyll- $a$ concentration, and the derived IOPs when using QAA and, presumably, other IOP algorithms.

The MM01 and PR05 models were further evaluated using the AERONET-OC dataset, which consists of 9824 samples from a total of 15 sites. Only $R_{r s}$ measurements at 412, 443, 488, 531, 547, 667 , and $869 \mathrm{~nm}$ were available, but the missing data at 678 and $748 \mathrm{~nm}$ does not affect significantly the $R_{r s}$ retrievals as tested using the Hydrolight simulations. Similar conclusions to those obtained with simulated $R_{r s}$ are drawn for the model-retrieved $R_{r s}$ and $R_{r s}$ ratios, confirming the theoretical results, but with relatively higher bias and RMSE probably due to the uncertainties existing in field measurements, and the IOP variability not captured by both models. In any case, the uncertainty in reconstructing $R_{r s}$ is much smaller than typical POLYMER atmospheric correction errors obtained against in-situ measurements. Again, the model-retrieved chlorophyll- $a$ concentration does not agree well with the AERONET-OC values, which may partly result from the application of non-site-specific bio-optical algorithms. Therefore, it is recommended that the reconstructed water reflectance, not the retrieved model parameters, should be used in bio-optical algorithms.

The three-parameter PR05 model was also evaluated using the Hydrolight simulations, to examine whether using more parameters would improve the reconstruction of the water reflectance. Reconstruction was improved with three parameters, but slightly. Using more parameters, however, increases computation time and is less likely to guarantee convergence of the spectral matching scheme. The trade-off is between efficiency/robustness and accuracy. It is concluded that the two-parameter PR05 model is preferred and appropriate to represent the reflectance of a wide range of Case 1 and case 2 waters in spectral-matching atmospheric correction schemes such as POLYMER, and probably other (e.g., statistical) one-step inversion schemes, at least until progress in atmospheric correction necessitates otherwise.

Author Contributions: Conceptualization, methodology and investigation: J.T. and R.F.; writing-original draft preparation: J.T.; writing — review and editing: R.F., D.R., F.S., and G.Z.; supervision: R.F.

Funding: The National Aeronautics and Space Administration (NASA) provided funding for this research under grants NNX14AM3G and NNX14AQ46A.

Acknowledgments: The authors wish to thank Zhongping Lee, University of Boston, for generating and making available the synthesized IOCCG data set, Giuseppe Zibordi, Joint Research Centre of the European Union, and the principal investigators, scientists, and technicians responsible for collecting, processing, and archiving the AERONET-OC data, and John McPherson, Scripps Institution of Oceanography, for technical help. Zibordi provided 
useful comments on the manuscript. The support of NASA's Ocean Biology/ Biogeochemistry Program, managed by Paula Bontempi and Laura Lorenzoni, is gratefully acknowledged.

Conflicts of Interest: The authors declare no conflict of interest.

\section{References}

1. Frouin, R.J.; Franz, B.A.; Ibrahim, A.; Knobelspiesse, K.; Ahmad, Z.; Cairns, B.; Chowdhary, J.; Dierssen, H.M.; Tan, J.; Dubovik, O.; et al. Atmospheric Correction of Satellite Ocean-Color Imagery During the PACE Era. Front. Earth Sci. 2019, 7, 145. [CrossRef]

2. Chomko, R.M.; Gordon, H.R. Atmospheric correction of ocean color imagery: use of the Junge power-law aerosol size distribution with variable refractive index to handle aerosol absorption. Appl. Opt. 1998, 37, 5560. [CrossRef] [PubMed]

3. Land, P.E.; Haigh, J.D. Atmospheric correction over case 2 waters with an iterative fitting algorithm: relative humidity effects. Appl. Opt. 1997, 36, 9448. [CrossRef] [PubMed]

4. Stamnes, K.; Li, W.; Yan, B.; Eide, H.; Barnard, A.; Pegau, W.S.; Stamnes, J.J. Accurate and self-consistent ocean color algorithm: simultaneous retrieval of aerosol optical properties and chlorophyll concentrations. Appl. Opt. 2003, 42, 939. [CrossRef] [PubMed]

5. Kuchinke, C.P.; Gordon, H.R.; Franz, B.A. Spectral optimization for constituent retrieval in Case 2 waters I: Implementation and performance. Remote Sens. Environ. 2009, 113, 571-587. [CrossRef]

6. Shi, C.; Nakajima, T.; Hashimoto, M. Simultaneous retrieval of aerosol optical thickness and chlorophyll concentration from multiwavelength measurement over East China Sea. J. Geophys. Res.: Atmos. 2016, 121, 14084-14101. [CrossRef]

7. Gordon, H.R. Removal of atmospheric effects from satellite imagery of the oceans. Appl. Opt. 1978, $17,1631$. [CrossRef]

8. Sathyendranath, S.; Prieur, L.; Morel, A. A three-component model of ocean colour and its application to remote sensing of phytoplankton pigments in coastal waters. Int. J. Remote Sens. 1989, 10, 1373-1394. [CrossRef]

9. D'Sa, E.J.; Miller, R.L.; Del Castillo, C. Bio-optical properties and ocean color algorithms for coastal waters influenced by the Mississippi River during a cold front. Appl. Opt. 2006, 45, 7410. [CrossRef]

10. D'Sa, E.J.; DiMarco, S.F. Seasonal variability and controls on chromophoric dissolved organic matter in a large river-dominated coastal margin. Limnol. Oceanogr. 2009, 54, 2233-2242. [CrossRef]

11. Komick, N.M.; Costa, M.P.F.; Gower, J. Bio-optical algorithm evaluation for MODIS for western Canada coastal waters: An exploratory approach using in situ reflectance. Remote Sens. Environ. 2009, 113, 794-804. [CrossRef]

12. O'Donnell, D.M.; Effler, S.W.; Strait, C.M.; Leshkevich, G.A. Optical characterizations and pursuit of optical closure for the western basin of Lake Erie through in situ measurements. J. Great Lakes Res. 2010, 36, 736-746. [CrossRef]

13. Steinmetz, F.; Deschamps, P.-Y.; Ramon, D. Atmospheric correction in presence of sun glint: application to MERIS. Opt. Express 2011, 19, 9783. [CrossRef] [PubMed]

14. Müller, D.; Krasemann, H.; Brewin, R.J.W.; Brockmann, C.; Deschamps, P.-Y.; Doerffer, R.; Fomferra, N.; Franz, B.A.; Grant, M.G.; Groom, S.B.; et al. The Ocean Colour Climate Change Initiative: I. A methodology for assessing atmospheric correction processors based on in-situ measurements. Remote Sens. Environ. 2015, 162, 242-256.

15. Müller, D.; Krasemann, H.; Brewin, R.J.W.; Brockmann, C.; Deschamps, P.-Y.; Doerffer, R.; Fomferra, N.; Franz, B.A.; Grant, M.G.; Groom, S.B.; et al. The Ocean Colour Climate Change Initiative: II. Spatial and temporal homogeneity of satellite data retrieval due to systematic effects in atmospheric correction processors. Remote Sens. Environ. 2015, 162, 257-270. [CrossRef]

16. Morel, A.; Maritorena, S. Bio-optical properties of oceanic waters: A reappraisal. J. Geophys. Res.: Ocean. 2001, 106, 7163-7180. [CrossRef]

17. Park, Y.-J.; Ruddick, K. Model of remote-sensing reflectance including bidirectional effects for case 1 and case 2 waters. Appl. Opt. 2005, 44, 1236. [CrossRef] 
18. IOCCG. Remote Sensing of Inherent Optical Properties: Fundamentals, Tests of Algorithms, and Applications; Reports of the International Ocean-Colour Coordinating Group, No. 5; Lee, Z.-P., Ed.; IOCCG: Dartmouth, NS, Canada, 2006.

19. Zibordi, G.; Mélin, F.; Berthon, J.-F.; Holben, B.; Slutsker, I.; Giles, D.; D'Alimonte, D.; Vandemark, D.; Feng, H.; Schuster, G.; et al. AERONET-OC: A network for the validation of ocean color primary products. J. Atmos. Ocean. Technol. 2009, 26, 1634-1651. [CrossRef]

20. Lee, Z.; Carder, K.L.; Arnone, R.A. Deriving inherent optical properties from water color: A multiband quasi-analytical algorithm for optically deep waters. Appl. Opt. 2002, 41, 5755. [CrossRef]

21. Morel, A.; Gentili, B. Diffuse reflectance of oceanic waters III Implication of bidirectionality for the remote-sensing problem. Appl. Opt. 1996, 35, 4850. [CrossRef]

22. Ruddick, K.G.; De Cauwer, V.; Park, Y.-J.; Moore, G. Seaborne measurements of near infrared water-leaving reflectance: The similarity spectrum for turbid waters. Limnol. Oceanogr. 2006, 51, 1167-1179. [CrossRef]

23. Westberry, T.K.; Boss, E.; Lee, Z. Influence of Raman scattering on ocean color inversion models. Appl. Opt. 2013, 52, 5552. [CrossRef] [PubMed]

24. Nelder, J.A.; Mead, R. A simplex method for function minimization. Comput. J. 1965, 7, 308-313. [CrossRef]

25. Morel, A. Optical modeling of the upper ocean in relation to its biogenous matter content (case I waters). J. Geophys. Res. 1988, 93, 10749. [CrossRef]

26. Pope, R.M.; Fry, E.S. Absorption spectrum (380-700 nm) of pure water II Integrating cavity measurements. Appl. Opt. 1997, 36, 8710. [CrossRef]

27. Smith, R.C.; Baker, K.S. Optical properties of the clearest natural waters (200-800 nm). Appl. Opt. 1981, 20, 177. [CrossRef]

28. Gregg, W.W.; Carder, K.L. A simple spectral solar irradiance model for cloudless maritime atmospheres. Limnol. Oceanogr. 1990, 35, 1657-1675. [CrossRef]

29. Bricaud, A.; Babin, M.; Morel, A.; Claustre, H. Variability in the chlorophyll-specific absorption coefficients of natural phytoplankton: Analysis and parameterization. J. Geophys. Res. 1995, 100, 13321. [CrossRef]

30. Bricaud, A.; Morel, A.; Babin, M.; Allali, K.; Claustre, H. Variations of light absorption by suspended particles with chlorophyll a concentration in oceanic (case 1) waters: Analysis and implications for bio-optical models. J. Geophys. Res.: Ocean. 1998, 103, 31033-31044. [CrossRef]

31. Roesler, C.S.; Perry, M.J.; Carder, K.L. Modeling in situ phytoplankton absorption from total absorption spectra in productive inland marine waters. Limnol. Oceanogr. 1989, 34, 1510-1523. [CrossRef]

32. Kirk, J.T.O. Light and Photosynthesis in Aquatic Ecosystems; Cambridge University Press: Cambridge, UK, 1994; ISBN 0521459664.

33. Voss, K.J. A spectral model of the beam attenuation coefficient in the ocean and coastal areas. Limnol. Oceanogr. 1992, 37, 501-509. [CrossRef]

34. Gordon, H.R.; Morel, A.Y. Remote Assessment of Ocean Color for Interpretation of Satellite Visible Imagery: A Review; Lecture Notes on Coastal and Estuarine Studies; American Geophysical Union: Washington, DC, USA, 1983; Volume 4, ISBN 0-387-90923-0.

35. Loisel, H.; Morel, A. Light scattering and chlorophyll concentration in case 1 waters: A reexamination. Limnol. Oceanogr. 1998, 43, 847-858. [CrossRef]

36. Morel, A.; Bélanger, S. Improved detection of turbid waters from ocean color sensors information. Remote Sens. Environ. 2006, 102, 237-249. [CrossRef]

37. Robinson, W.D.; Franz, B.A.; Patt, F.S.; Bailey, S.W.; Werdell, P.J. Masks and flags updates. In SeaWiFS Postlauch Technical Report Series; NASA/TM-2003-206892; Hook, S.B., Firestone, E.R., Eds.; National Aeronautics and Space Administration, Goddard Space Flight Center: Greenbelt, MD, USA, 2003; Volume 22, pp. $34-40$.

38. Krasemann, H.; Müller, D. Ocean Colour Climate Change Initiative (OC-CCI)_Phase Two: Product Validation and Algorithm Selection Report, Part 1-Atmospheric Correction; Technical Report AO-1/6207/09/I-LG, D2.5, 4.0.3; ESRIN, European Space Agency: Frascati, Italy, 2017; p. 26.

39. O’Reilly, J.E.; Maritorena, S.; Mitchell, B.G.; Siegel, D.A.; Carder, K.L.; Garver, S.A.; Kahru, M.; McClain, C. Ocean color chlorophyll algorithms for SeaWiFS. J. Geophys. Res.: Ocean. 1998, 103, 24937-24953.

40. Werdell, P.J.; Bailey, S.W. An improved in-situ bio-optical data set for ocean color algorithm development and satellite data product validation. Remote Sens. Environ. 2005, 98, 122-140. [CrossRef]

41. Hu, C.; Lee, Z.; Franz, B. Chlorophyll $a$ algorithms for oligotrophic oceans: A novel approach based on three-band reflectance difference. J. Geophys. Res.: Ocean. 2012, 117. [CrossRef] 
42. Seegers, B.N.; Stumpf, R.P.; Schaeffer, B.A.; Loftin, K.A.; Werdell, P.J. Performance metrics for the assessment of satellite data products: an ocean color case study. Opt. Express 2018, 26, 7404. [CrossRef]

43. Maritorena, S.; Siegel, D.A.; Peterson, A.R. Optimization of a semianalytical ocean color model for global-scale applications. Appl. Opt. 2002, 41, 2705. [CrossRef]

44. Werdell, P.J.; Franz, B.A.; Bailey, S.W.; Feldman, G.C.; Boss, E.; Brando, V.E.; Dowell, M.; Hirata, T.; Lavender, S.J.; Lee, Z.; et al. Generalized ocean color inversion model for retrieving marine inherent optical properties. Appl. Opt. 2013, 52, 2019. [CrossRef]

45. Lenoble, J.; Herman, M.; Deuzé, J.L.; Lafrance, B.; Santer, R.; Tanré, D. A successive order of scattering code for solving the vector equation of transfer in the earth's atmosphere with aerosols. J. Quant. Spectrosc. Radiat. Transf. 2007, 107, 479-507. [CrossRef]

46. Tanre, D.; Herman, M.; Deschamps, P.Y.; de Leffe, A. Atmospheric modeling for space measurements of ground reflectances, including bidirectional properties. Appl. Opt. 1979, 18, 3587. [CrossRef] [PubMed]

47. Fitzpatrick, M.F.; Brandt, R.E.; Warren, S.G.; Fitzpatrick, M.F.; Brandt, R.E.; Warren, S.G. Transmission of solar radiation by clouds over snow and ice Surfaces: A parameterization in terms of optical depth, solar zenith angle, and surface albedo. J. Clim. 2004, 17, 266-275. [CrossRef]

(C) 2019 by the authors. Licensee MDPI, Basel, Switzerland. This article is an open access article distributed under the terms and conditions of the Creative Commons Attribution (CC BY) license (http://creativecommons.org/licenses/by/4.0/). 